\title{
Anatomische Veränderungen bei Entzündung der Aderhaut.
}

\author{
Von \\ Prof. Dr. Ernst Fuchs \\ in Wien.
}

Mit Taf. XI und XII, Fig. 1-21, und 5 Figuren im Text.

Es gibt Fälle, in welchen man an der äussern Oberfläche der Aderhaut, zwischen dieser und der Sklera, feste Membranen, ja selbst Schwarten findet. Solche Fälle bildeten den Ausgangspunkt meiner Untersuchungen, durch welche ich feststellen wollte, anf welche Weise derartige Bindegewebsneubildungen entstehen. Ich sah zu diesem Zwecke die in meinem Besitze befindlichen zahlreichen Präparate von schwerer eitriger oder plastischer Entzündung der innern Augenhäute, sowie die von intraokulären Blutungen genau durch.

Die Fälle von Entzïndung, welche ich hier im Auge habe, sind solche, welche durch Infektion von aussen her nach Perforation der Augenhïllen entstanden sind oder auf metastatischem Wege. Derartige Entzündungen werden je nach ihrer Schwere als Panophthalmitis, als eitrige und als plastische Tridocyclitis benannt ${ }^{1}$ ).. Ich werde

1) Diese Bezeichnungen sind zum mindesten ungenau. Plastische und eitrige Entzündung lässt sich nicht scharf trennen, denn es gibt zahlreiche Übergänge. Es geschieht ferner oft, dass in demselben Auge ein Teil des Exsudates zu Eiter sich verflüssigt, ein anderer zu einer bindegewebigen. Schwarte wird. Auch der Name Iridocyclitis oder Iridochorioiditis ist ungenau, indem nebst der Iris und den oberfächlichen Lagen des Ciliarkörpers hauptsächlich die Netzhaut an der Entzündung and an der Lieferung des Exsudates teilnimmt, während die Aderhaut erst in zweiter Linie, in vielen Fällen gar nicht in Betracht kommt. Da die entzündeten Membranen ihr Exsudat in die Hohlrảume des Auges, also in die Augenkammern und auch in den Glaskörper absetzen, hat Straub den Namen Hyalitis vorgeschlagen. Die gewöhnlichen Bedenken gegen diesen Ausdruck teile ich nicht. Den pathologischen Vorgang kennen wir: der entzündungserregende Reiz geht zumeist vom Glaskörperraume aus, worauf die dadurch betroffenen innern Augenhaute ihr Exsudat in den Glaskörper absetzen. Dieser 
nun zuerst die Veränderungen schildern, welche bei der frischen Entzündung vorkommen, und in einem zweiten Abschnitte mich mit den oben erwähnten bindegewebigen Verdichtungen an der äussern Fläche der Aderhaut befassen.

\section{Frische eitrige Entzündung der innern Augenhäute.}

In den Fällen frischer Entzündung ist die Beteiligung der einzelnen Augenhäute recht verschieden. Solange man einzelne Fälle für sich untersucht, erhält man den Eindruck, als ob es sich um zufällige Verschiedenheiten handle. Erst beim Vergleich einer grossen Zahl solcher Fälle untereinander drängt sich dem Untersucher die Gesetzmässigkeit auf, welche den Variationen zu Grunde liegt. Das

spielt dabei eine passive Rolle, wobei es ja nicht darauf ankommt, ob etwa einzelne der spärlichen Glaskörperzellen sich auch teilen oder nicht. Ich sehe aber kein Hindernis, trotz dieses passiven Verhaltens des Glaskörpers den Prozess als Hyalitis zu bezeichnen, wenn man sich etwa dahin einigt, entzündliche Prozesse in einzelnen Fällen nach demjenigen Gewebe zu benennen, in welches das Exsudat abgesetzt wird; man hat mit Recht die Keratitis zum Vergleiche herangezogen. Es wäre dies also, wie bei jeder Benennung, Sache des Übereinkommens. lch erhebe aber gegen den Ausdruck "Hyalitis" den Einwand, dass ex zu allgemein ist und dass dexaselben sehr verschiedene Krankheitsprozesse zu Grunde liegen können, insofern sie nur eine Exsudation in den Glaskörper hervorbringen. Es sind die Membranen, welche Exsudate liefern, in den einzelnen Fällen verschieden, z. B. das einemal vorzüglich der Ciliarkörper, das anderemal die Netzhaut oder die Aderhaut, und es kann auch die Art und die Ätiologie der Entzündung ganz verschieden sein. Es darf daher nicht wundernehmen, wenn Straub (Bericht über den internation. ophthalm. Kongress in Utrecht 1899, S. 410) die verschiedensten Ursachen für Hyalitis angibt, indem er Entzündung durch Infektion von aussen her entstanden, metastatische Entzündung, Entzündung aus lronstitutioneller Ursache, ja selbst gewisse Fäle ron Glaukom zur Hyalitis rechnet. Ich finde darin einen Rücksehritt, gerade so, als ob wir die Diagnose Hypopyon stellen würden, anstatt Keratitis oder Iritis zu diagnostizieren. Wir trachten ja, unsere Diagnosen immer präziser zu gestalten und an die Stelle der klinischen Diagnosen mehr und mehr die anatomischen zu setzen. - In den Fällen von Entzündung, welche den Gegenstand dieser Untersuchung bilden, sind vor allem die Augenhänte beteiligt, welche das Auge innen auskleiden, also die Iris, der Ciliarkörper (speziell dessen retinaler Überzug) und die Netzhaut; erst in zweiter Linie kommt die Aderhaut in Betracht. Die innern Augenhäute sind deswegen beteiligt, weil die entzündungserregenden Schädlichkeiten zuerst auf deren innere Oberfläche einwirken. Nach Analogie der Endocarditis, Endometritis usw. würde es mir am meisten logisch erscheinen, dieses Krankheitsbild in seinen verschiedenen Varietäten mit dem Namen der Endophthalmitis septica zu belegen, wobei "septisch" im weitern Sinne des Wortes nur bedeuten sollte, dass die Entzündung durch Infektion entstanden ist. 
Auge ist für dieses Studium ein besonders dankbares Objekt, indem sich hier auf kleinem Raume, gleichsam in einem Mikrokosmos, dieselben Veränderungen verfolgen lassen, welche sich in andern Körperteilen in grossen Verhältnissen abspielen, z. B. bei einer septischen Peritonitis.

Bei der grossen Menge von einzelnen anatomischen Befunden, welche die Literatur aufweist, gibt es doch nur wenige Arbeiten, welche die Veränderungen bei der eitrigen Entzündung des Augeninnern in zusammenfassender Weise behandeln. Eine der ersten von diesen ist die Arbeit von Sattler ${ }^{1}$ ). Dieser macht über die anatomischen Veränderungen bei der eitrigen Chorioiditis die Angabe, dass die zellige Infiltration sich zuerst in den nach aussen auf die Kapillarschicht folgenden, noch pigmentlosen Lagen des elastischen Netzwerkes zeigt, erst später in der Capillaris selbst. Zuletzt wird die Aderhaut in ihrer ganzen Dicke von Zellen durchsetzt. Greeff ${ }^{2}$ ) findet auch, dass die Infiltration in den Innenschichten der Aderhaut beginnt, während die ganz nach aussen liegende Schicht, die Suprachorioidea, erst sehr spät von der Infiltration ergriffen wird. Wenn in dieser sich reichlich Exsudat ansammelt, so entsteht Abhebung der Aderhaut. Seltener erfolgt Absetzung von Exsudat auf der innern Oberfläche der Chorioidea.

Ginsberg ${ }^{3}$ ) bestätigt ebenfalls, dass die Infiltration in den innern Aderhautschichten beginnt und die Schichte der grossen Getässe sowie die Suprachorioidea lange davon frei bleiben, dagegen von flüssigem Exsudate durchsetzt sind. Buchanan ${ }^{4}$ ) stellt in übersichtlicher Weise die Verhältnisse bei den eitrigen Entzündungen dar, soweit sie den Ciliarkörper betreffen. Schöblis) war der erste, welcher auf Grund der Untersuchung einer grössern Zahl von Augen mit Panophthalmitis den Nachweis erbringt, dass es hauptsächlich die Netzhaut ist, welche das eitrige Exsudat im Glaskörper liefert. Ru ge ${ }^{6}$ ), welcher die grösste Zahl von Fällen anatomisch verwertet, gibt an, dass bei den eitrigen Augenentzündungen in der Nähe des Abscesses im Glaskörper auch die Netzhaut eitrig infiltriert ist. Die Aderhaut kann ganz normal bleiben; in den meisten Fällen aber erkrankt sie auch und zwar in den äussern Schich-

1) Über den feinern Ban der Chorioidea des Menschen. Dieses Archiv, Bd. XXII. 2. Abt. S. 42.

2) Lehrbuch der speziellen pathologischen Anatomie, herausgegeben von Orth. Auge, S. 285 u. f.

3) Grundriss der patholog. Histologie des Auges. Berlin 1903. S. 232 u.f.

4) Transact. of the Ophthalm. Society of the United Kingdom. Vol. XXI. p. 208.

5) Areh. f. Augenheilk. Bd. XXI. S. 378, 1890.

6) Dieses Arch. Bd. LVII. S. 401. 
ten stärker als in den innern, weshalb die Erkrankung der innern Schichten derjenigen der äussern nachzufolgen, nicht voranzugehen scheint.

Bevor ich an die Besprechung der Veränderungen in der Uvea bei der eitrigen Entzündung des Augeninnern gehe, muss ich zur Vermeidung von Missverständnissen eine Form von Uveitis erwähnen, welche nicht hierher gehört, obwohl sie auch nach perforierenden Verletzungen auftritt. Sie ist dadurch charakterisiert, dass sie vor allem eine dichte Infiltration der Uvea selbst, sei es in diffuser, sei es in Knötchenform setzt, welche manchmal zu sehr bedeutender Verdickung dieser Membran führt, ferner, dass sie ausserordentlich leicht auf das andere Auge als sympathische Entzündung ïbergeht. Ich zweifle nicht, dass diese Form durch besondere, bisher nicht bekannte Bakterien hervorgebracht wird. Dem gegenüber soll sich die vorliegende Arbeit nur mit jener Form der Entzündung der Uvea beschäftigen, welche eine Teilerscheinung der akuten Entzündung der gesamten innern Augenhäute nach perforierender Verletzung ist. Diese Form unterscheidet sich von der vorigen ätiologisch dadurch, dass sie durch die gewöhnlichen Eiterungserreger verursacht wird. Sie unterscheidet sich anatomisch von der andern Form dadurch, dass hier nicht die Aderhaut der Hauptherd der Entzündung ist, sondern dass diese erst sekundär in Mitleidenschaft gezogen wird; das zuerst und hauptsächlich betroffene Gewebe ist die Netzhaut selbst und der Netzhautüberzug des Ciliarkörpers. Es besteht zwar bei dieser Form auch oft eine starke Infiltration der Aderhaut, welche aber, akut entstanden, ebenfalls wieder rasch zurückgeht und nicht zur chronischen Verdickung führt; dagegen kommt es oft zu ausgiebiger Exsudation auf die vordere oder hintere Fläche der Aderhaut, welche zur Schwartenbildung Veranlassung geben $\operatorname{kann}^{1}$ ).

1) Schirmer unterscheidet in seiner umfassenden Besprechung der traumatischen Entzündungen (dieses Arch., Bd.LIII, S.1) neben der seltenen Uveitis serosa zwei Formen: 1. rein fibrinöse Uveitis, bei welcher Iris und Ciliarkörper reichlich fibrinöses Exsudat produzieren, während an der Aderhaut nur kleinzellige, meist herdweise Infiltration, aber beine Exsudat- und Schwartenbildung nachweisbar ist. 2. Uveitis purulenta, bei welcher Eiter in der Vorderkammer oder im Glaskörper klinisch nachweisbar ist. Schirmer fügt allerdings der Uveitis fibrinosa noch eine Gruppe von Fällen hinzu, bei welchen die klinische Untersuchung ebenfalls nur fibrinöse Exsudation nachweist, der Hauptherd aber ein Glaskörperabscess ist. Damit meint er wohl Mischformen der fibrinösen unà eitrigen Uveitis. Ruge (loc. eit.) hat die Aufstellung Schirmers durch zahlreiche anatomische Befunde genauer präzisiert. Er hebt dabei mit Recht hervor, dass es auch Mischformen gibt. Diese können nach Ruge entweder von vornherein auf Mischinfektion beruhen, oder es kann aus einer ursprünglich 
Bei der gewöhnlichen akuten Entzündung des Augeninnern nach Verletzungen (Endophthalmitis septica) werden die entzündungserregen-

eitrigen Uveitis durch Abschwächung des Virus eine fibrinös-plastische sich entwickeln. Die von Schirmer und Rnge aufgestellten zwei Formen der Uveitis fallen mit jenen zusammen, welche ich selbst oben unterschieden habe. Ich bin ebenfalls überzeugt, dass es sich um zwei grundverschiedene Arten von Infektion handelt. Ich glaube nicht, dass es auch noch darauf ankommt, ob die Bakterien in das Gewebe der Uvea selbst oder ob sie in den Glaskörper eingebracht werden (Schirmer), und ebenso glaube ich nicht, wie Ruge, dass die eitrige Form durch Abschwächung in die andere - plastische - Form übergehen kann. Dass es Mischformen gibt, ist sicher, aber sie beruhen meiner Meinung nach auf gemischter Infektion. Ich habe mehrere solche Fäle anatomisch tntersucht und sie dadurch als Mischformen erkannt, dass sich im Präparate die beiden Formen der Entzündung deutlich auseinander halten liessen. So lag z. B. in einem meiner Fälle auf der äussern Oberfläche der Aderhaut eine mächtige Schwarte, welche von der auf die Verletzung folgenden alsuten Entzündung herruhrte. Daneben aber besteht eine frische dichte Infiltration der Aderhaut mit Lymphocyten und Gruppen von epitheloiden Zellen, wodurch die Aderhaut auf das Mehrfache verdickt ist. Dieses junge Gewebe wnehert an verschiedenen Stellen in die alte Schwarte hinein, welche sich dabei ganz passiv verhält.

Wenn Schirmer als Charakteristicum der akut eitrigen Form den Glaskörperabscess anführt, so kann ich denselben nicht als konstantes Symptom anerkennen. Das Kennzeichen der einen Form ist nicht etwa, dass das Exsudat eitrig ist oder dass es im Glaskörper liegt, sondern dass das Exsudat anf die Oberfläche der Membranen ahgesetzt wird, dagegen die chronisehe Infiltration des Stromas selbst fehlt, welche die andere Form charakterisiert. Auch bei der Infektion des Auges mit den gewöhnlichen Eiterungserregern wird der Glaskörperabscess fehlen, wenn entweder die Infektion nicht bis in den Glaskörperraum vorgedrungen ist, oder wein bei Infektion des Glaskörpers diese nicht virulent genug ist, um Eiterbilding hervorzurufen, so dass es nur zu Schwartenbildung kommt. Ich kann mich daher auch mit der Bezeichnung der beiden Formen als der eitrigen und der fibrinös-plastischen nicht befreunden. Während ich für die eine Form den Ausdruck Endophthalmitis septica für geeignet halte, würde ich die andere am liebsten die sympatbisierende nennen, weil nach meiner Erfahrung in der grossen Mehrzahl dieser Fälle das andere Auge erkrankt. Dennoch ist diese Bezeichnung nicht anwendbar, weil die sympathische Entzundung eben doch manchmal ausbleibt, sei es, dass das verrletzte Auge rechtzeitig enucleiert wurde, sei es, dass die Utbertragung aus irgend welchen Ursachen nicht zu stande kam. Vielleicht würde für diese Form der Name Chorioiditis parenchymatosa passen, weil hier eben die Exsudation hauptsächlich im Parenchym der Aderhaut selbst besteht (dies gilt freilich auch für die Fälle sogenannter Chorioiditis exsudativa).

Wenn wir also nach einer Verletzung fulminante Eiterung, Panophthalmitis oder nahestehende Formen, eintreten sehen, so wird über die Diagnose kein Zweifel sein. Wenn es sich aber um weniger schwere Entzündungen handelt, mit Pupillarmembxan, Schwarten in der hinteren Kammer usw., so kann diese Entzündung der einen oder der andern Form angehören und wir haben heute 
den Keime entweder in den Kammerraum oder in den Glaskörperraum eingebracht. Im erstern Falle können die Keime und damit die Entzündung auf den Bereich der Kammern beschränkt bleiben, es können aber auch die Keime aus den Kammern nachträglich in den Glaskörperraum gelangen. Dies hängt von verschiedenen Faktoren $a b$, vor allem von der Virulenz der Keime und damit ihrer Vermehrungs- und Ausbreitungstähigkeit, ferner von den anatomischen Verhältnissen im Augapfel. Der Kammerraum ist vom Glaskörperraum durch ein Diaphragma, Linse und Zonula Zinnii, getrennt, welches dem Vordringen der Entzündungserreger Widerstand leistet. Ist dieses Diaphragma geschädigt, z. B. nach Staroperation, so wird bei stattgehabter Infektion des Kammerraumes die Ausbreitung der Entzündung auf den Glaskörper erleichtert. Darum führte wohl in der voraseptischen Zeit die Staroperation viel häufiger zur Vereiterung des Augapfels als die Iridektomie.

Die Tatsache, dass eine ursprünglich in den Kammerraum gesetzte Infektion auf den Glaskörper iibergegriffen hat, ist klinisch daran zu erkennen, dass die entzündlichen Erscheinungen plötzlich zunehmen, die Lichtempfindung rasch sich verschlechtert und ein leichter Exophthalmus eintritt.

Die Infektion des Glaskörperraumes kann auch von der Aderhaut oder Netzhaut ausgehen, wenn - bei metastatischer Ophthalmie - in diese Membranen Entzündungserreger mit dem Blutstrom gelangen. Endlich kommt es in seltenen Fällen vor, dass von hinten bei Entzündungen in der Orbita durch die unverletzte Sklera hindurch Keime in das Augeninnere eindringen.

Sind die Binnenräume des Auges infiziert, so wirken die Entzündungserreger auf die Oberfläche der innern Augenhäute, nämlich Iris, Ciliarkörper und Netzhaut. Ich sehe in der vorliegenden Arbeit von den Entzündungen der Iris ab und ziehe nur die Membranen in Betracht, welche den Glaskörperraum begrenzen.

\section{Pars ciliaris retinae.}

An der innern Oberfläche des Ciliarkörpers ist es die retinale Zellenlage, welche zuerst reichlich von ausgewanderten Leukocyten durchsetzt wird. Dieselben sammeln sich an der Oberfläche des Ciliar-

noch kein sicheres Anzeichen, diese beiden Formen, welche anatomisch so gut unterschieden sind, klinisch auseinanderzuhalten. So lange dies aber nicht der Fall ist, werden wir noch manches Auge wegen der Möglichkeit sympathischer Entzündung entfernen müssen, das ohne Gefahr hätte bleiben können. 
körpers an und bilden das oft massenhafte Exsudat, welches diesen Fällen - bei gleichzeitiger Beteiligung der Iris - den Namen der Iridocyclitis verschafft hat. Dabei geht der Prozess anfangs wenig in die Tiefe. Die äussere, pigmentierte Zellenlage der Pars ciliaris ist durcheinandergeworfen und teilweise zerstört, indem die Pigmentzellen und ihre Trümmer durch den aus den Ciliarkörpergefässen austretenden Exsudationsstrom mitgenommen und in die Exsudatmassen hineingeschwemmt werden (Fig. 1a). Dieses Exsudat ist daher bäufig pigmenthaltig. Auch die unpigmentierte Lage der retinalen Zellen spielt bei der Entziundung hauptsächlich eine passive Rolle. Die Leukocyten dringen zwischen den Zellen durch und heben sie einzeln oder im Zusammenhange von ihrer Unterlage ab (Fig. 1 b). Im bindegewebigen Stroma der Ciliarfortsätze ist die Infiltration gewöhnlich geringer, selbst wenn die Oberfäche derselben schon von einem Eiterbelage überzogen ist. Auch insofern ist der Prozess anfangs oberflächlich, als vor allem die am meisten hervorragenden Teile der Ciliarfortsätze in Entzündung begriffen sind. In den Nischen und Gruben dagegen ist die Entzündung sehr gering; dieselben sind von geronnener Flüssigkeit mit vereinzelten Eiterkörperchen erfüllt und sowohl die beiden retinalen Zellenlagen (Fig. $1 c, d$ ) als auch das Stroma der Ciliarfortsätze ist wenig verändert. Dies zeigt, wie diejenigen Gewebsteile zuerst erkranken, zu welchen zuerst vom Glaskörper her die entzündungserregende Schädlichkeit gelangt. Später greift allerdings die Infiltration tiefer in das Gewebe der Ciliarfortsätze ein und es entsteht auch eine mässige Infiltration des Ciliarmuskels, ja ich habe in einem Falle in dem letztern eine ganz umschriebene dichte Infiltration gefunden, gleich einem beginnenden kleinen Abscesse. Auf der andern Seite gibt es Fälle, wo die Infiltration der tiefen Teile während des ganzen Krankheitsverlaufes niemals eine nennenswerte Höhe erreicht. - Im flachen Teile des Ciliarkörpers fehlen die geschützten Buchten; der ganze retinale Überzug ist in lebhafter Entziindung begriffen, und daher ist auch die Infiltration des darunterliegenden Stromas hier oft stärker als im gefalteten Teile des Ciliarkörpers (Fig. 3g).

\section{Retina.}

Nebst dem retinalen Überzuge des Ciliarkörpers ist es die eigentliche Netzhaut, welche bei Infektion des Glaskörpers in erster Linie erkrankt. In den leichten Fällen, sowie bei den schweren im Beginne, beschränkt sich die Entzïndung auf die innern Netzhautlagen 
(Fig. 4b). Sie sind von Leukocyten durchsetzt, welche sich in besonders grosser Menge um die Wand der Netzhautvenen, in geringerer Menge auch um die Wand der Netzhautarterien ansammeln, so dass man von einer Periphlebitis sprechen kann. Die Leukocyten treten dann ans dem Gewebe der Netzhaut auf die innere Oberfläche derselben aus und sammeln sich in den äussersten Schichten des Glaskörpers an (Fig. 4a). Sehr häufig wird durch diese Zellen oder durch einen serösen Erguss eine Abhebung der Membrana limitans. interna verursacht. Haftet dieselbe stellenweise noch an, so bildet. sie Arkaden an der innern Oberfläche der Netzhaut; oft ist sie aber in grosser Ausdehnung und ohne Zerreissung abgehoben.

Die Infiltration der Netzhaut ist an zwei Punkten am stärksten, im vordersten und im hintersten Teile der Netzhant, also an der Ora serrata und in der Umgebung des Sehnervenkopfes 1). Die vordersten Teile der Netzhaut sind eben diejenigen, zu welchen der Entzündungsreiz zuerst gelangt. Die starke Entzündung der Netzhaut um den Sehnervenkopf sowie die Entzündung des Sehnervenkopfes selbst ist wahrscheinlich so zu erklären, dass auch an diese Stelle der Entzündungsreiz früher kommt als an die mittlern Partien der Netzhaut. Ich glaube, dass dieses durch Vermittlung des Canalis hyaloideus geschieht, in welchem sich die entziindungserregenden Substanzen besonders rasch nach rückwärts verbreiten und den Sehnervenkopf treffen ${ }^{2}$ ).

Wir sehen also, dass die Entzündung in der Netzhaut sich nicht einfach in der Kontinuität der Membran ausbreitet, wie etwa die erysi-

1) Fine Ausnahme davon machen jene Fälle, in welchen der Ausgangspunkt der Entzündung einer Netzhautpartie besonders benachbart ist, z. B. ein im Glaskörper nahe der Netzhantoberfläche liegender Fremdkörper. In diesen Fällen wird sich natürlich dieser Netzhautteil zuerst entzünden.

2) Die so bald eintretende Beteiligung des Sehnervenkopfes seheint mir die Ursache zu sein, dass man nach Verletzungen mit folgender Infeltion oft sehon so frühzeitig die Lichtempfindung herabgesetzt oder erloschen findet. Da man dies mit Recht als ein Anzeichen der Infelktion des Glaskörpers ansieht, gilt es als eine Indikation zur Enucleation. Man ist dann zuweilen erstannt, bei der Sektion des Auges nicht die weitgehenden Veränderungen zu finden, welche man auf Grund der fehlenden Lichtperzeption erwartete, wie ausgedehnte eitrige Entzündung der Netzhaut, Abhebung derselben usw.; es bestehen vielmehr oft nur geringe Entzündungserscheinungen an der Papille und Umgebung wie entzündliches ödem und mässige Leukocytenansammlung. Dieselben genägen kaum, die vollständige Unterbrechung der Leitung in den Sehnervenfasern zu erklären, so dass man daneben noch eine Lähmung der Fasern durch Vergiftung mit den Balkterientoxinen annehmen möchte. - Auf der andern Seite erklärt die Geringfügigkeit der anatomischen Veränderungen, dass selbst bei mangelhafter Lichtempfindung das Sehvermögen später wieder zurückkehren kann, wenn die Entzündung im ganzen günstig abläuft. 
pelatöse Entzündung in der Haut, sondern dass sie überall dort primär auftritt, wo die entziindungserregenden Substanzen die innere Oberfläche der Netzhaut treffen, und an jenen Orten früher und stärker, welche von diesen Substanzen rascher erreicht werden. Diese Art der Verbreitung der Entzündung erhellt auch aus Fällen, wo nach Extraktion einer Cataracta Wundinfektion aufgetreten war. Hier kann die eitrige Retinitis entweder gleichzeitig über den ganzen vordem Abschnitt verbreitet sein, oder sie sitzt hauptsächlich im untern Teile der Netzhant - also entgegengesetzt dem Orte der infizierten Wunde und hier entwickelt sich der Glaskörperabscess. Wenn man von solchen Fällen absieht, wo etwa die Bakterien durch ein in das Auge eingeführtes Instrument direkt in den untern Teil des Glaskörpers gebracht wurden, so bleibt für die gewöhnlichen Fälle nur die Annahme übrig, dass von der infizierten Wunde aus das Exsudat durch Senkung zuerst nach abwärts gelangte und den untern Teil des Glaskörpers und der Netzhaut zur Entzündung brachte. Auch in einigen Fäilen von perforierenden Geschwüren mit nachheriger Infektion des Augeninnern habe ich ähnliche Verhältnisse gefunden.

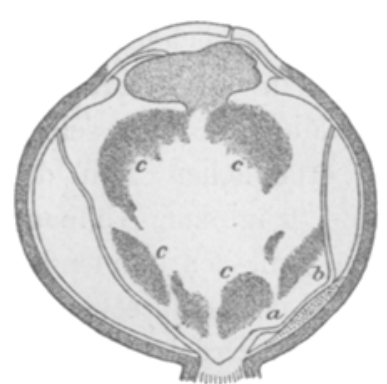

Fig. I. Eisensplitterverletzung vor 3 Wochen. Perforierende Hornhautwunde, Linsentrübung. Netzhantablosung bis anf à Strecke $a b$, wo eine alte Verwachsung zwischen Netzhath und Aderhaut besteht, $c$ Eiter im Glaskôrpar.

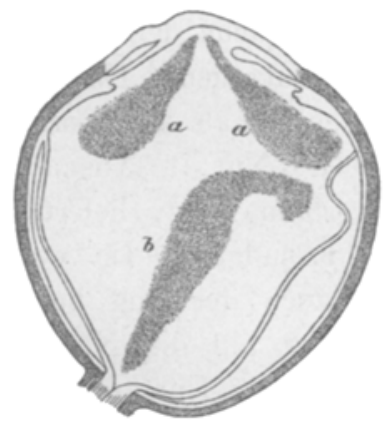

Fig. T. Perforierende Fornhautverletzung vor 16 Tagen. Vordere Synechie, Netzhantablosung. $a$ a Fitex im vordem, $b$ im hintern Teile des Glaskörpers.

Bei Ansteigen der Entzündung wird die Netzhaut in ihrer ganzen Dicke von Eiterkörperchen durchsetzt, welche sich dann auch auf der innern Oberfäche der Netzhaut zu einer zusammenhängenden Exsudatschichte ansammeln und zusammen mit dem Produkte der Ciliarfortsätze den Glaskörperabscess bilden (Fig. I-IV). Entsprechend der besonders intensiven Beteiligung der vordersten Netzhautteile inklusive Pars ciliaris retinae einerseits und der hintersten Netzhautteile 
anderseits kommt es häufig vor, dass dieser Abscess sich aus zwei Teilen zusammensetzt, einem vordern, welcher auf den Ciliarfortsätzen und hinter der Linse liegt, und einem zweiten in den hintern Teilen des Glaskörpers (Fig. I). In Fig. II sieht man förmlich, wie der Eiter $b$ den Canalis hyaloideus erfüllt. Später vereinigen sich die isolierten Exsudatklumpen zu einer einzigen, von der abgelösten Netzhaut eingehüllten Eitermasse.

Die weitern Veränderungen der Netzhaut, welche besonders für das Verhalten der Aderhaut wichtig sind, betreffen die Abhebung der Netzhaut und den Durchbruch derselben.

Die Abhebung der Netzhaut erfolgt bei eitriger Entziundung derselben in der Regel frühzeitig und wird bald total. Sie wird verursacht durch Setzung eines zumeist serösen Ergusses unter die Netzhaut. Diese ist es auch, welche den grössten Teil dieses Exsudates liefert und nicht die Aderhaut, trotz ihres grössern Getässreichtums. Als Beweis dafür führe ich an, dass die Leukocyten, welche dem Exsudate gewöhnlich nur in geringer Menge beigemischt sind, auf der äussern Oberfläche der Netzhaut zu liegen pflegen (Fig. 2) und sich auch in geringer Menge in den äussern Netzhautschichten finden; auf der Oberfläche der Aderhaut liegen dagegen nur wenige, ja oft keine Exsudatzellen. Das auf der Aderhaut zurïckgebliebene Pigmentepithel verhält sich normal und ebenso in der Regel die Aderhaut selbst. Nur in Ausnahmsfällen, wo die Aderhaut selbst frühzeitig ergriffen wird, liefert diese einen erheblichen Teil des subretinalen Exsudates. Im weitern Verlaufe trägt zur Abhebung der Netzhaut auch der Zug bei, welchen das nun schrumpfende Glaskörperexsudat auf die Netzhaut ausübt. Dem entsprechend ist im Frühstadium der Entzündung der intraokuläre Druck häufig erhöht, in spätern Stadien herabgesetzt.

Je frïhzeitiger die Netzhaut abgehoben wird, desto mehr bleibt die Aderhaut von der Entzïndung verschont. Die Netzhaut zusammen mit der subretinalen Flüssigkeit verhindert offenbar genügend den Zutritt der entzïndungserregenden Substanzen zur Aderhaut. Diese ist daher manchmal selbst bei schwerer Glaskörpereiterung nahezu normal oder nur in geringem Grade von einer diffusen Infiltration eingenommen, welche später spurlos wieder verschwindet. Wenn dann der Entzündungsprozess abgelaufen ist, hat man ein atrophisches Auge, in welchem der Ciliarkörper und die abgehobene Netzhaut ein geschrumpftes Exsudat einschliessen, während an der Aderhaut keine Veränderungen zu finden sind. Nur die Glashaut derselben zeigt oft 
reichliche drusige Excrescenzen, die sich in solchen Fällen mit Vorliebe entwickeln.

Die Abhebung der Netzhaut bleibt selbstverständlich an solchen Stellen aus, wo etwa durch eine vorausgegangene Erkrankung eine Verwachsung derselben mit der Aderhaut stattgefunden hat (Fig. I $a b$ ). Aber auch in Fällen, wo keine Verwachsung dieser Art besteht, kann die Abhebung der Netzhaut während des akuten Stadiums der Entzündung ausbleiben und sich erst später einstellen, wenn das Glaskörperexsudat schrumpft. Ich habe einen Fall untersucht, in welchem die ganze innere Oberfläche der Netzhaut mit Eiter belegt und die innern Netzhautschichten in lebhafter Eiterung begriffen waren, während keine nennenswerte Abhebung vorhanden war; an der äussern Oberfläche der Netzhaut lag an vielen Stellen gar kein Exsudat, an andern nur eine ganz dünne Schicht von Eiterkörperchen (Fig. III makroskopisch

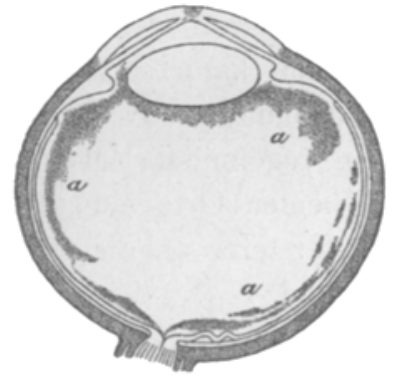

Tig. III. Perforierende Hornhautverletzung ror 8 Tagen. a a E Eiter im Glasteörper. und Fig. 4 mikroskopisch, demselben Auge entnommen). Ähnlich waren die Verhältnisse in einem zweiten Falle.

Die Abhebung der Netzhaut wird dann im Frühstadium einer eitrigen Retinitis vermisst, wenn bei starker Exsudation auf die Innenfläche der Netzhaut eine solche an der Aussenfläche fehlt oder sehr unbedeutend, nur aus einzelnen Zellen bestehend, ist. Warum der Strom der Exsudation in manchen Fällen in so einseitiger Weise sich ergiesst, lässt sich aus dem anatomischen Befunde nicht entnehmen. Es ist klar, dass in solchen Fällen durch das Anliegen der eiternden Netzhaut an die Aderhaut die Entzündung sehr bald auf diese übergreift. Am meisten wird die Aderhaut den vom Glaskörper herkommenden Entzündungsreizen ausgesetzt, wenn die Netzhaut durchbrochen ist. Dies geschieht zuweilen schon frühzeitig an umschriebener Stelle durch Schrumpfung des Exsudates, welches auf der Netzhaut liegt, während diese selbst durch Entzündung brüchig geworden ist. In einem meiner Fälle sieht man die Netzhaut am Rande eines im Glaskörper liegenden Eiterklumpens zeltartig emporgehoben und an der Spitze der Erhebung eingerissen; durch den Riss dringen Eiterzellen aus dem Glaskörper unter die Netzhaut hinein. Häufiger geschieht der Durchbruch dex Netzhaut durch Nekrose derselben an solchen Stellen, wo die Entzündung eine besondere Höhe erreicht. 
Die nekrotische Netzhaut zerfällt und kann bis zur Unkenntlichkeit im eitrigen Exsudate verschwinden, welches dann in unmittelbare Berührung mit der Aderhant tritt.

\section{Chorioidea.}

Die Aderhaut spielt bei den in Rede stehenden Prozessen eine sekundäre Rolle, im Gegensatze zur ältern Auffassung, welche hauptsächlich der Aderbaut die Eiterproduktion zuschrieb, wohl mit Rücksicht auf den grossen Gefässreichtum dieser Membran. Die Aderhaut kann selbst bei schwerer eitriger Entzündung des Augeninnern nahezu unverändert bleiben. "Nahezu", indem an zwei Orten doch regelmässig etwas entzündliche Infiltration nachzuweisen ist. Die beiden Orte sind der vordere und der hintere Rand der Aderhaut, ersterer an die Ora serrata, letzterer an den Sehnervenkopf angrenzend.

Am vordern Rande der Aderhaut entsteht die Infiltration durch Fortschreiten der Entzüindung in der Kontinuität der Uvea, also rom flachen Teile des Ciliarkörpers her. Dieser ist von der in voller Eiterung befindlichen Pars ciliaris retinae überzogen und daher stets stark infiltriert. An der Ora serrata beginnt nun die eigentliche Netzhaut. Dieselbe gibt der Aderhaut Schutz gegen die im Glaskörper vorhandenen Entzündungserreger, denn sie ist viel dicker als die Pars ciliaris retinae und ist auch nicht mit der Oberfläche der Chorioidea verwachsen wie diese. Besonders sicher wird der Schutz, wenn die Netzhautabhebung schon hier beginnt. Die Wirkung dieses Schutzes bemerkt man in Fig. 3 schon an dem Verhalten des Pigmentepithels. Dieses ist vor der Ora serrata in Infiltration und Auflösung begriffen $(e)$, hinter derselben aber ziemlich normal $(f)$. Dagegen erstreckt sich die Entzündung in Stroma der Uvea $(g)$ noch von der Ora serrata ein Stück weit nach hinten $(b)$. Diese Entzündung ist eben nicht vom Glaskörper aus direkt hervorgerufen, sondern vom entzündeten Ciliarkörper noch eine Strecke weit fortgeleitet. Sie verliert sich aber bald.

Die zweite Stelle der Aderhaut, welche regelmässig infiltriert gefunden wird, ist der hintere Rand derselben (Fig. 2). Hier ist die Entzïndung rom Sehnervenkopf übergeleitet. Die Papille und die angrenzende Netzhaut nehmen immer besonders frühzeitig und besonders stark an der eitrigen Netzhautentzündung teil (S. 398). Die Überleitung derselben auf die Aderhaut wird nun dadurch begünstigt, dass diese hier in fester Verbindung mit dem Sehnervenkopfe steht. 
Der Rand der Aderhaut ist an den Sehnervenkopf angewachsen und an dieser Stelle geht das Kapillarnetz der Aderhaut in dasjenige des Sehnerven über. In unmittelbarer Umgebung des Sehnervenkopfes liegt ferner die eiternde Netzhaut gewöhnlich der Aderhaut auf, da die Netzhautabhebung in diesem hintersten Teile noch fehlt oder unbedeutend ist $\left.{ }^{1}\right)$. Die Infiltration der Aderhaut ist am stärksten knapp am Sehnerven. Sie setzt hier scharf gegen den kaum infiltrierten Bindegewebsring des Sehnerven ab, und auch die Substanz des Sehnervenkopfes selbst ist weniger infiltriert als die Aderhaut. Das gleiche gilt auch bezüglich des Verhältnisses zwischen der Aderhaut und der ihr aufliegenden Netzhaut neben der Papille; die Netzhaut ist hier meist weniger reich an Leukocyten als die Aderhaut. In dieser ist die Infiltration entweder in allen Schichten gleich stark oder in den äussern Schichten stärker als in der innersten. Die Infiltration nimmt mit der Entfernung vom Sehnervenkopf rasch ab und verschwindet einige Millimeter davon gänzlich.

Die beiden regelmässig erkrankten Stellen der Aderhaut sind also der vordere und der hintere Rand derselben. Der Weg, auf welchem diese Erkrankung zu stande kommt, ist aber für diese beiden Orte verschieden. Der vordere Rand erkrankt durch Fortpflanzung der Entzündung vom Ciliarkörper her in der Kontinuität der Uvea, der hintere Rand dagegen durch die Einwirkung des entzündeten Sehnervenkopfes und der angrenzenden Netzhaut.

Das Verhalten des übrigen, weitaus grössten Teiles der Aderhaut hängt hauptsächlich von der Netzhant ab. Wenn diese frühzeitig abgehoben wird, kann die Aderhaut bis auf die genannten Partien normal bleiben. Dies war z. B. der Fall in dem in Fig. II abgebildeten Auge, in welchem nach einer perforierenden Verletzung eitrige Retinitis mit Glaskörperabscess entstanden war. Das Auge war 16 Tage nach der Verletzung enucleiert worden.

In andern Fällen, namentlich in etwas ältern, findet man trotz der frühzeitigen Abhebung der Netzhaut doch eine Infiltration der Aderhant, welche in der Regel nicht besonders intensiv ist und sich diffus über die Aderhant erstreckt. Diese Infiltration geht gewöhn-

1) Erst später, wenn die schrumpfenden Exsudate den Netzhauttrichter nach vorn ziehen, entsteht jenes Bild der Abhebung, welches den anatomischen Untersuchem am meisten geläufig ist, dass nämlich die Netzhaut als zusammengefalteter Strang in der Fortsetzung des Sehnervenstammes gerade nach vorn zieht, ja dass manchmal der Sehnervenstamm selbst ein wenig in das Augeninnere hineingezogen ist. 
lich wieder zurück, so dass nach Ablauf der entzïndlichen Erscheinungen, am atrophischen Bulbus, die Aderhaut im grossen und ganzen wieder normal gefunden wird. Diese diffuse Entzündung der Aderhaut kann vom vordern Rande derselben in der Kontinuität der Membran fortgeleitet sein. Man wird dies annehmen, wenn die Infiltration von vorne nach rückwärts allmählich und gleichmässig abnimmt, oder wenn sie weiter nach hinten reicht, als die Entzündung in der Netzhaut. In andern Fällen, wo die Infiltration ziemlich gleichmässig über die ganze Aderhaut sich erstreckt, ist sie wahrscheinlich auf den Einfluss der subretinalen Flüssigkeit zu beziehen, in welche von der entzündeten Netzhaut reizende Substanzen gelangen. Da sich diese in der subretinalen Flïssigkeit wohl ziemlich gleichmässig verteilen, so ist auch die Wirkung derselben auf die Aderhaut eine gleichmässige. Würde die Infiltration der Aderhaut direkt durch die Netzhaut induziert sein (trotz deren Abhebung), so müsste man entsprechend den Stellen, wo die Netzhaut in besonders starker Eiterung begriffen ist, wo ihrer innern Fläche ein Abscess anliegt, auch die Aderhaut besonders stark infiltriert finden, was durchaus nicht der Fall ist.

Sowie einerseits trotz frühzeitiger Abhebung der Netzhaut eine mässige Infiltration der Aderhaut auftreten kann, so kann umgekehrt diese Infiltration ausbleiben, trotzdem die eiternde Netzhaut an die Aderhaut angelegt bleibt. Dies kommt aber verhältnismässig selten vor und kann nur so erklärt werden, dass in diesen Fällen die Netzhaut ein besonders dichtes Filter gegen die entzündungserregenden Stoffe bildete und dieselben nicht bis zur Aderhaut gelangen liess. Die Fig. 4 ist dem Falle entnommen, welcher in Fig. III abgebildet und auf S. 401 erwähnt ist. Es hatte vor acht Tagen eine perforierende Hornhautverletzung stattgefunden und die Netzhaut war trotz lebhafter eitriger Entzündung noch nicht abgehoben. Auf der innern Oberfläche der Netzhaut liegt ein eitriger Belag ( $a$ in Fig. III u. Fig. 4) und die zellige Infiltration lässt sich bis zur Schicht der bipolaren Zellen verfolgen. A ber schon die äussere plexiforme Schicht enthält nur vereinzelte Exsudatzellen und die äussersten Netzhautschichten sind nahezu frei davon. Die Aderhaut ist hier so gut wie normal. Es ist freilich nicht ausgeschlossen, dass später, wenn die Netzhaut noch lange anliegend geblieben wäre, zuletzt doch die Aderhaut auch von. der eitrigen Entzündung ergriffen worden wäre.

Wenn man von derartigen Ausnahmsfällen absieht, muss als Regel aufgestellt werden, dass in den Fällen, wo die Netzhaut mit 
der Aderhaut länger in Beriihrung bleibt, die Aderhaut direkt von der Netzhaut aus schwer erkrankt. Je länger und in je grösserer Ausdehnung die Netzhaut auf der Aderhaut liegen bleibt, desto mehr entzündet sich die letztere. Die Stellen stärkster Infiltration der Aderhaut entsprechen gewöhnlich nicht genau denjenigen,' wo die Netzhaut am meisten infiltriert ist. Dies erklärt sich wohl dadurch, dass die Bedingungen, welche den Übergang der Entzündung von der Aderhaut auf die Netzhaut beherrschen, mehrfache sind und verschiedene Kombinationen zulassen. Ich hebe nur zwei Punkte hervor, welche in dieser Beziehung von Wichtigkeit sein können: wie weit die Entzündung der Netzhaut in die äussern Schichten derselben vordringt, und ob die Netzhaut wirklich ganz der Aderhaut anliegt, oder doch eine ganz dünne Schicht Flüssigkeit beide trennt.

Noch rascher und intensiver wird die Entzündung von der Netzhaut auf die Aderhaut übertragen, wenn nicht bloss ein Aneinanderliegen, sondern eine Verwachsung beider Membranen besteht, weil dann die entzündungserregenden Substanzen noch leichter von einer Membran in die andere übergehen. Der in Fig. I dargestellte Fall illustriert das Gesagte.

Es war ein Eisensplitter in den Glaskörper eingedrungen, dort liegen geblieben und infolgedessen eine Glaskörpereiterung eingetreten. Drei Wochen nach der Verletzung wurde das Auge enucleiert. Die in Eiterung befindliche Netzhaut ist überall abgehoben bis auf eine $4 \mathrm{~mm}$ im Durchmesser haltende Stelle, unweit der Papille, wo an Stelle eines alten Herdes von Retinochorioiditis eine innige Verwachsung zwischen Netzhaut und Aderhaut besteht (Fig. Iab). Die Netzhaut ist hier atrophisch, teilweise pigmentiert und bei Feblen des Pigmentepithels fest mit der Glasmembran der Aderhaut verwachsen. Entsprechend der Verwachsungsstelle besteht eine diehte, zellige Infiltration der Aderhaut und ein Ödem im suprachorioidealen Raume, welche Verändernngen sich eine kurze Strecke weit über die Verwachsungsstelle hinaus erstrecken. Mit Ausnahme dieser Partie aber ist die Aderhaut normal, dank der frühzeitigen Abhebung der Netzhaut. Nur am vordern und hintern Rande der Aderhaut besteht wie immer eine schmale Zone mässiger Infiltration.

Besonders schwer ist die Entzündung der Aderhaut dort, wo die ihr aufliegende Netzhaut nekrotisch zertällt; hier kann auch die Aderhaut durch und durch nekrotisch werden. Es ist zuerst die Einwirkung der nekrotischen Netzhaut und nach Zerfall derselben die unmittelbare Einwirkung des eiternden Glaskörpers auf die Aderhaut, was diese so schwer affiziert. Die unmittelbare Einwirkung des Glaskörpers auf die Aderhaut kommt auch in jenen Fällen zur Geltung, 
wo eine lokale Zerreissung der Netzhaut der im Glaskörperraume enthaltenen Flüssigkeit den Zutritt zur Aderhaut gestattet.

Wir haben bisher zwei Wege kennen gelernt, auf welchen bei Infektion des Glaskörpers die Entzündung auf die Aderhaut sich verbreitet: erstens vom Glaskörper resp. Netzhaut aus und zweitens in geringerem Masse - vom flachen Teile des Ciliarkörpers aus in der Kontinuität der Uvea. Es gibt aber noch einen dritten Weg, nämlich die Einwirkung der Entzündungserreger auf die äussere Oberfläche der Aderhaut (ich habe dabei nicht ${ }^{t}$ die Fälle im Auge, wo die Entzündung von der Sklera ausgeht und von welchen ich später sprechen werde, sondern ich betrachte jetzt nur jene Fälle, in welchen, wie oben gesagt, die Infektion in den Glaskörper gesetzt wurde). Dies geht so zu: Es besteht eine intensive Entzündung des flachen Teiles des Ciliarkörpers. Von diesem aus gelangen entzündungserregende Stoffe in den suprachorioidealen Raum und führen hier zu einer Exsudation. Diese kann auf die Nachbarschaft der entzündeten Teile der Uvea beschränkt bleiben. Es kann aber auch von hier aus gleichsam eine Infektion des ganzen suprachorioidealen Raumes entstehen und dadurch eine selbständige starke Exsudation in denselben stattfinden, wie ich weiter unten, wo von der Suprachorioidea die Rede sein wird, ausführlicher zeigen werde. Von dem suprachorioidealen Exsudate aus wird dann die Aderhaut selbst und zwar an ihrer äussern Seite angegriffen. Dies wird besonders deutlich in solchen Fällen, wo bei frühzeitiger Abhebung der Netzhaut die Aderhaut von vorneher verschont geblieben ist. In Fig. 5 ist eine Stelle abgebildet, wo der suprachorioideale Raum von eitrigem Exsudate $d$ erfüllt ist. Die vordersten, der Aderhaut anliegenden suprachorioidealen Lamellen zeigen gleichfalls eine wenn auch geringere Infiltration, und ebenso auch noch die Aderhaut selbst in ihren hintern Schichten. Nach vorne zu nimmt aber die Infiltration rasch $a b$, so dass die Choriocapillaris $a$ fast frei davon ist. Praktisch, d. h. in bezug auf die Lieferung des Exsudates komint dieser Weg der Verbreitung der Entzündung wenig in Betracht, doch gehört dessen Kenntnis dazu, um einen vollständigen Begriff von dem Ablaufe der pathologischen Vorgänge bei eitriger Infektion des Augeninnern zu haben.

Die entzündete Aderhaut ist nicht bloss in ihrem Gewebe infiltriert, sondern setzt auch das von ihren Gefässen gelieferte Exsudat an ihre rordere und hintere Fläche ab. Das Exsudat ist meist mehr serös, selten zellenreich oder gar eitrig. - In dem subretinalen Exsudate sind die Zellen nicht gleichmässig in der Flüssigkeit verteilt, 
sondern sie liegen meist auf der hintern Oberfläche der Netzhaut, teilweise auch auf der vordern Fläche der Aderhaut, oder sie bilden einzelne Zellenklumpen. Es ist schwer, im einzelnen Falle zu entscheiden, wie weit an der Lieferung des Exsudates zwischen Netzhaut und Aderhaut jede der beiden Membranen beteiligt ist. Da zuerst die Netzhaut vom Entzündungsreize getroffen wird und sich in ihren vordern Schichten in Eiterung befindet, wird man auch dieser den Hauptanteil an der Lieferung des Exsudates zuschreiben müssen. Man ist um so mehr dazu berechtigt, wenn bei starker. Abhebung der Netzhaut die hintere Fläche derselben einen Belag von Eiterzellen trägt, während anderseits auf dem Pigmentepithel wenige oder keine Zellen liegen und wenn das Pigmentepithel selbst in Ordnung ist. Bei stürmischer Exsudation aus der Aderhaut bleibt das Pigmentepithel nicht normal. Man sieht dasselbe auf grössere Strecken abgehoben, durch Exsudat von der Glasmembran getrennt und stellenweise in Fetzen abgestossen, welche im subretinalen Exsudate schwimmen. - Zusammenfassend kann man sagen, dass der Erguss zwischen Netzhaut und Aderhaut vorwiegend serös zu sein pflegt und Eiter nur an ganz umschriebenen Stellen angetroffen wird. Daher finden wir denn auch nach Ablauf der akuten Entzündung die innere Oberfläche der Aderhaut oft wieder normal.

In einer kleinen Zahl von Fällen kommt es später zur Bildung bindegewebiger Schwarten, welche oft sehr dicht sind und auch nicht selten verknöchern. Dieselben sind gewöhnlich der vordern Fläche der Aderhaut aufgelagert, zwischen Pigmentepithel und Glasmembran, oder sie liegen noch in den innern Schichten der Aderhaut selbst. Diese Schwarten sind ein späteres Produkt der Entzündung, entstanden durch chronische Wucherung der entzündeten Aderhaut. Sie sind den Schwarten an die Seite zu setzen, welche die Oberfläche des Ciliarkörpers bedecken. Während aber diese in ältern Fällen traumatischer Entzündung kaum je fehlen, bestehen die Schwarten an der vordern Fläche der Aderhaut nur in einem kleinen Bruchteile der Fälle. Dies entspricht ganz dem Verhältnisse, in welchem Ciliarkörper und Aderhaut an der Entzündung teilnehmen. Der retinale Überzug des Ciliarkörpers und das darunter liegende Stroma befinden sich im akuten Stadium stets in heftiger Entzündung, während die Aderhaut oft nur wenig an der akuten Entzündung teilnimmt, da sie eben durch die Netzhaut geschützt ist.

Die Exsudation, welche von der Aderhaut auf die hintere Fläche derselben geht, soll jetzt besprochen werden. 


\section{Suprachorioidea.}

Das Verhalten der Suprachorioidea bei den eitrigen Entziundungen der innern Augenhäute ist noch wechselnder als das der Aderhaut, weil die Bedingungen für die Teilnahme an der Entzündung hier noch komplizierter sind. Die entzündungserregenden Substanzen müssen nicht bloss das Filter der Netzhaut, sondern auch noch das der Uvea passieren, bevor sie an die Suprachorioidea gelangen. Das Verhalten dieser hängt daher vor allem von dew Verhalten der Uvea ab. Man findet den suprachorioidealen Raum gewöhnlich an jenen Stellen von Exsudat erfüllt, wo die dariuberliegende Uvea infiltriert ist. Der Übergang der Entzündung von der Uvea auf den Suprachorioidealraum erfolgt verschieden rasch und verschieden intensiv. Die Fig. 6 rührt von einem besonders heftig verlaufenden Falle her, in welchem schon am vierten Tage nach der Verletzung das Auge zur Enucleation gekommen war. Nicht bloss die Netzhaut befand sich in voller Eiterung, sondern auch die Aderhaut war in ihren vordern Teilen schon eitrig infiltriert, ja stellenweise geradezu in einen Abscess verwandelt. An der abgebildeten Stelle, welche ungefähr $4 \mathrm{~mm}$ hinter der Ora serrata lag, war schon das ganze Gewebe der Aderhaut im Eiter untergegangen, die Glasmembran und das Pigmentepithel zerstört und die Eitermassen selbst in der Mitte nekrotisch (b). Trotzdem ist im suprachorioidealen Raume ( $d$ u. $e)$ nur eine unbedeutende Menge geronnener Flüssigkeit mit sehr spärlichen Eiterzellen angesammelt. Da dieser Fall so frisch ist, würde wahrscheinlich in den nächsten Tagen eine ausgiebige Exsudation auch in den suprachorioidealen Raum erfolgt sein.

In andern weniger heftigen Fällen kann die Infiltration selbst dauernd auf die Uvea beschränkt bleiben und nicht auf die Suprachorioidea übergreifen. Die Fig. 7 entstammt einem Falle, in welchem vor acht Tagen ein Zündhütchensplitter in das Auge gedrungen war. Derselbe war nahe der Papille an die Netzhaut angeflogen und hatte diese sowie die innersten Schichten der Aderhaut durchgeschlagen, um dann in den untern Teil des Glaskörpers. herabzufallen. Die Netzhaut zeigt einen Riss, dessen Ränder aber frei von Infiltration sind. In der Aderhaut dagegen liegt ein dichtes Iufiltrat, welches durch das Loch in der Glasmembran in den subretinalen Raum vorquillt $(a)$ und dabei das Pigmentepithel zur Seite drängt. Nach hinten hat es aber die suprachorioidealen Lamellen 
nur etwas zusammengedrängt; zwischen denselben liegen nur ganz vereinzelte Zellen und befindet sich keine freie Flüssigkeit ${ }^{1}$ ).

Wenn man von den Ausnahmställen wie den eben erwähnten absieht, muss man als Regel aufstellen, dass bei Infiltration der Uvea auch im suprachorioidealen Raume ein Exsudat gefunden wird, welches auch örtlich der Infiltration der Uvea entspricht. Daher trifft man die Exsudation am frühesten in jenem Teile des suprachorioidealen Raumes, welcher dem flachen Teile des Ciliarkörpers und der angrenzenden vordersten Zone der Aderhaut entspricht, also ungefähr entlang der Ora serrata (weiter vorne sind die suprachorioidealen Lamellen durch den dicken Ciliarmuskel von dem entzündeten Stroma der Ciliarfortsätze getrennt). Hier besteht daher gewöhnlich ein Ödem des suprachorioidealen Raumes, resp. eine flache Abhebung der Aderhaut2). - Nebst dem vorderen. Rande der Aderhaut ist es

1) Der Ausgangspunkt des Entzündungsreizes ist hier die verletzte Stelle der Glasmembran. Yon dieser Stelle aus verbreitet sich die Infiltration viel weiter innerhalb der Aderhaut selbst, als durch die Dicke der Aderhaut nach hinten. Die Fntzündung dringt also nicht nach allen Seiten mit gleicher Geschwindigkeit vor, wie z. B. die Schallwellen in der Luft. Sie schreitet schneller, weil leichter, innerhalb des Gewebes der Aderhaut fort, als sie von der Aderhaut auf die suprachorioidealen Lamellen übergeht, obwohl diese ein lockeres Gefüge besitzen und daher dem Vordringen der Infiltration keinen mechanischen Widerstand entgegensetzen. Dies wirft ein Streiflicht auf die Lymphströmung innerhalb der Aderhaut. Es ist anzunehmen, dass die entzündungserregenden Substanzen und mit diesen die Infiltration sich am leichtesten in derselben Richtung ausbreiten, welcher die Saftströmung folgt. Wenn man daher aus der Ausbreitung der Entzündung auf die Wege der Saftströmung zurückschliessen darf, so ergibt sich, dass nicht an jeder Stelle der Aderhaut die Lymphe derselben sofort und leicht in den suprachorioidealen Raum übertritt, sondern dass sie zunächst in der Aderhaut weiterströnt, bis sie an der einen oder andern Stelle den Übertritt vollzieht. Wahrscheinlich sind die zarten Endothelhäutchen in der Aderhaut das Hindernis für den freien Übertritt dex Lymphe, so dass dieser nur an jenen Stellen geschieht, wo die Endothelhäutchen von den hindurchtretenden Blutgefässen durchbrochen werden (Sattler, loc. cit. S. 24). Auch die später zu gebenden Beispiele von verhältnismässiger Unabhängigkeit der Exsudation in der Aderhaut und in der Suprachorioidea sprechen in demselben Sinne.

*) Greeff (loc. cit. S. 286 und S. 292) führt die Flüssigkeitsansammlung im suprachorioidealen Raume darauf zurtick, dass das auf den Ciliarfortsätzen liegende Exsudat die Absonderung des Kammerwassers an der freien Oberfläche verhindert, so dass sich dasselbe im suprachorioidealen Raume anstaut. Ich verstehe nicht, wie sich Greeff diesen Vorgang vorstellt. Jedenfalls sprechen die anatomischen Befunde uicht für diese Erklärung. Ich konnte durch Vergleichen zahlreicher Präparate von frischer Entzündung mit serösem Ergusse im suprachorioidealen Raume feststellen, dass ein bestimmtes Verhältnis zwischen 
der hintere, an den Sehnerven angrenzende Rand derselben, welcher gewöhnlich entzündet ist (S. 402). Hier ist aber die Exsudation im suprachorioidealen Raume stets gering, weil die feste Anheftung der Aderhaut an die Sklera eine Ausdehnung dieses Raumes hier nicht erlaubt. Bei isolierter Infiltration der Aderhaut an andern Stellen bleibt das Ödem der Suprachorioidea häutig auf die entsprechende Gegend beschränkt, bei ausgebreiteter Entzündung der Aderhaut verbreitet sich auch die Exsudation im suprachorioidealen Raume. Sie ist dann fast immer in den vordern Partien stärker als in den hintern, wo sie in den leichtern Fällen oft ganz fehlt. Dies hat seinen Grund in der innigen Verbindung der Aderhaut mit der Sklera im hintern Abschnitte, namentlich aber in der Gegend der Macula lutea.

Stärkere Exsudation im Suprachorioidealraume tritt ein, wenn dieser, an irgend einer Stelle von der Aderhaut aus gleichsam infiziert, nun selbständig in ganzer Ausdebnung erkrankt, wie dies auf S. 406 schon beiläufig erwähnt wurde. Es obliegt mir, den Beweis zu führen, dass eine derartige Exsudation wirklich als Ausdruck einer gewissermassen selbständigen Entzündung vorkommt. Ich finde den Beweis in folgenden Tatsachen: 1. Es kann ein ausgedehntes entzündliches Ödem im suprachorioidealen Raume vorhanden sein, während die Aderhaut nur geringe Infiltration zeigt. Das Gesagte wird

der Exsudation auf den Ciliarfortsätzen einerseits und der Flüssigkeitsmenge im suprachorioidealen Raume anderseits nicht besteht. Sicher spricht gegen Greeffs Annahme, dass es zahlreiche Fälle gibt, sowohl frische mit eitrigem Exsudate als altere mit teilweise organisiertern Exsudate, in welchen die Ciliarfortsätze von einer dichten Exsudatschicht vollständig eingehüllt sind, ohne dass der geringste Erguss in den suprachorioidealen Raum zu bemerken wäre. Ich sehe kein Hindernis, die in vielen Fällen bestehende Flüssigkeitsansammlung im suprachorioidealen Raume ebenso zu erklären, wie die Flüssigkeitsansammlung, welche gewöhnlich gleichzeitig unter der Netzhaut besteht und deren Abhebung verursacht. Es handelt sich einfach um eine akute Transsudation aus den erweiterten Gefässen, um ein entzündliches Ödem, welches jede Entzündung begleitet, zumal wenn ein lockeres Gewebe oder gar Hohlräume wie der suprachorioideale und subretinale Raum eine grössere Flüssigkeitsansammlung gestatten. Dem. Charakter eines entzündlichen Ergusses entspricht auch die Beschaffenheit der suprachorioidealen Flüssigkeit, welche stets fibrinreich ist und oft reichliche Leukocyten und rote Blutkörperchen enthält. - Es ist selbstverständlich, dass der Erguss unter die Aderhaut bei frischer Entzitndung nicht verwechselt werden darf mit demjenigon, welchen man in atrophischen Augen tindet. Hier ist er gewöhnlich die Folge der mechanischen Abziehung der Ovea durch die schrumpfenden Schwarten im Glaskörper. 
durch den Vergleich der Figuren III und IV anschaulich gemacht. Beide Fälle sind dadurch bemerkenswert, dass trotz ziemlich ausgebreiteter Eiterung der Netzhaut diese kaum abgehoben ist und dass trotz Anliegens der Netzhaut die Aderhaut nur unbedeutend (am vordern und hintern Rande) ergriffen ist. In dem Falle III ist auch der suprachorioideale Raum verschont geblieben, in dem Falle IV dagegen, wo die eitrige Retinitis geringer war, besteht eine mächtige Ausdehnung dieses Raumes durch entzündliches Ödem. 2. Das entzündliche Ödem des Suprachorioidealraumes fällt in manchen Fällen mit der Infiltration der Uvea örtlich nicht zusammen. Es sind infiltrierte Stellen in der Aderhaut vorhanden, unter welchen die suprachorioidealen Lamellen kaum Exsudat zwischen sich schliessen, während in andern Teilen des Auges ausgebreitetes entzündliches Ödem der Suprachorioidea besteht bei ziemlich normaler Beschaffenheit der darüberliegenden Aderhaut. 3. Die entzündlichen Veränderungen in der Aderhaiut einerseits und in der Suprachorioidea anderseits stehen in bezug auf ihre Intensität oft nicht im rechten. Verhältnisse. Fig. 5 zeigt eine Stelle aus dem hintern Abschnitte eines Auges, welches eine Woche vor der Enucleation eine perforierende Verletzung am Hornhautrande erlitten hatte. Darauf war eine schwere

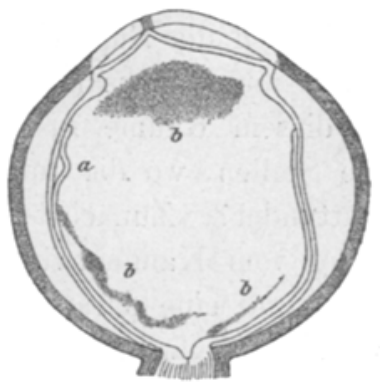

Fig. IV. Perferierende Hornhautverletang ror 8 Tagen. Fast totale Aderhautablösung, ganz umschriobene Netzluatablósung bei $a . \quad b b b$ Eiter im Glaskörper. eitrige Retinitis eingetreten, welche an einer Stelle zur Nekrose der Netzhaut und darunterliegenden Aderhaut geführt hatte. An der gezeichneten Stelle aber ist die Netzhaut fast normal, die Aderhaut mässig infiltriert, dagegen massenhaftes eitriges Exsudat zwischen den suprachorioidealen Lamellen. Es lässt sich leicht nachweisen, dass dieses von der weiter vorne gelegenen Stelle herstammt, wo die Nekrose der Netzhaut und Aderhaut besteht und unter beiden das eitrige Exsudat, teilweise selbst nekrotisch, in grösster Menge liegt. Von hier aus schiebt sich dasselbe im suprachorioidealen Raume bis in den hintern Teil des Auges vor. Dabei konstatiert man, dass 4. das Exsudat vorwiegend zwischen den mittlern Lamellen der Suprachorioidea liegt, während die der Aderhaut zunächst liegenden (ebenso wie die hintersten der Sklera anliegenden) Lamellen viel weniger eiterhaltig sind. Ein ähnliches Verhalten - Hauptmasse des Exsudates zwischen den mittlern Lamellen - lässt sich auch in 
andern Fällen konstatieren (Fig. 8f). Das relative Freibleiben der vordersten, an die Aderhaut grenzenden Lamellen beweist, dass das weiter hinten zwischen den mittlern Lamellen liegende Exsudat nicht an Ort und Stelle von der Aderhaut geliefert worden sein kann.

In den Fällen, wo die Entzündung im suprachorioidealen Raume sich weit ausbreitet, kann von hier aus die Aderhaut sekundär erkranken; die Entzündung greift dann an der hintern Oberfläche der Aderhaut an, wie auf S. 406 besprochen wurde.

Die selbständige Entzündung des suprachorioidealen Raumes muss man sich auf ähnliche Weise entstanden denken, wie etwa die der. gesamten Pleura in einem Falle, wo ein oberflächlicher Lungenherd die Pleura pulmonalis durchbricht, bevor es zu genügenden Adhäsionen zwischen dieser und der Pleura costalis gekommen ist. So wird auch der Suprachorioidealraum von einer entzündeten Stelle der Uvea aus gleichsam infiziert und die Entzündung breitet sich nun in diesem Raume rascher aus als in der Aderhaut. Welche sind die Stellen, wo die Infektion des Suprachorioidealraumes gewöhnlich stattfindet? Zunächst könnte man daran denken, dass die Entzündung vom Kammerwinkel ausgehe. Hier besteht ja oft ein Hypopyon und eine daran sich anschliessende Infiltration des lockern Gewebes der Kammerbucht; von hier bis zum vordern Ende des Suprachorioidealraumes ist nur ein kurzer Weg, welcher durch den Ansatz der Ciliarmuskelfasern an den Skleralsporn führt. Aber dieser Weg ist es nicht, welchen die Entzündung nimmt. Man findet gerade hier keine nennenswerte Infiltration und ebenso zeigt gerade das vordere Ende des Suprachorioidealraumes die geringste Ansammlung von Flüssigkeit und Zellen. Die Stelle des Übertrittes der Entzündung auf die Suprachorioidea ist vielmehr in der Regel der flache Teil der Ciliarkörpers. Hier ist einerseits die Entzündung des Uvealstromas am stärksten, anderseits der Weg zum Suprachorioidealraum am kürzesten. Weiter vorne schiebt sich der Ciliarmuskel zwischen Uvea und Suprachorioidea ein; weiter hinten, im Bereiche der Aderhaut, ist wieder die Entzündung des uvealen Stromas geringer. - Es kommt aber auch vor, dass vom rückwärtigen Teile der Uvea die Entzïndung zuerst auf die Suprachorioidea übergreift, wenn durch besondere Verhältnisse gerade hier Herde besonders intensiver Entzündung in der Aderhaut entstanden sind. Dass in gewissen Fällen der Suprachorioidealraum auch von der Sklera aus zuerst ergriffen werden kann, wird später besprochen werden.

Die Beschaffenheit des Exsudates im Suprachorioidealraume hängt 
von der Schwere der Entzündung ab. Zumeist ist es serös mit einer Beimengung von Leukocyten, wodurch es sich als entzündliches Transsudat kennzeichnet im Gegensatze zur fast zellfreien Flüssigkeit bei nicht entzündlicher Aderhantabhebung. Die Flüssigkeit ist in den Präparaten durch die Härtung geronnen und erscheint entweder homogen oder feinkörnig oder als zartes Fibrinnetz. Die Lamellen der Suprachorioidea werden durch den Erguss auseinandergedrängt und dadurch schön zur Anschauung gebracht. Die mittlern Lamellen schliessen am meisten Flüssigkeit zwischen sich. Die vordersten, der Aderhaut anliegenden und häufig auch die bintersten der Sklera benachbarten Lamellen sind weniger stark auseinandergedrängt. Fig. 8 zeigt, wie gerade die mittlern Lamellen ein Fibrinnetz einschliessen $(f)$, während die vordersten und hintersten Lamellen $(e$ und $g)$ ein weniger fibrinreiches Exsudat und auch weniger Exsudat im allgemeinen enthalten. Ich werde auf diese besondere Verteilung des Exsudates zurückkommen, wenn die Rede davon sein wird, dass die Schwarten, welche später in der Suprachorioidea entstehen, sowohl von der Uvea als von der Sklera durch lockere Suprachorioideallamellen getrennt zu sein pflegen. - Ausnahmsweise nimmt das entzündliche Ö̉em hauptsächlich die hintersten Lamellen der Suprachorioidea ein.

In einigen Fällen waren die Lamellen der Suprachorioidea in ganz besonderer Weise durch das Exsudat zerwuihlt und an vielen Stellen zerrissen (Fig. 9), ein Verhalten, das man wohl am besten durch besonders stürmisches Vordringen des aus den Gefässen austretenden Exsudates erklärt. Durch die Zerreissung der suprachorioidealen Lamellen entstehen manchmal grössere, bloss mit Flüssigkeit erfüllte Hohlräume.

Bei schwerer Entzündung ist das suprachorioideale Exsudat zellenreicher und an Stelle der einkernigen Zellen treten die mehrkernigen Eiterkörperchen. Auch ist oft dem Exsudate Blut beigemischt, entweder in Form grösserer Blutklumpen oder in feiner Verteilung der roten Blutkörperchen zwischen den Exsudatzellen (Fig. 9). Den schwersten Grad der Entzündung müssen wir annehmen, wenn das suprachorioideale Exsudat der Nekrose anheimfällt (Fig. 5).

Die Zellen können sich gerade so wie die Flüssigkeit vorwiegend zwischen den mittlern Lamellen der Suprachorioidea ansammeln; manchmal aber findet man mehr Zellen an der hintern Fläche der Aderhaut, besonders aber an der innern Oberfläche der Sklera. In einem Falle der letzten Art waren die Zellen in der Aderhaut und 
zwischen den suprachorioidealen Lamellen in mässiger Zahl und grösstenteils einkernig. Die innere Oberfläche der Sklera dagegen trug einen dichten Belag von Eiterzellen, welche sich vereinzelt auch noch zwischen die innern Lagen der Sklera verfolgen liessen. Hier war also nicht bloss die Zahl, sondern auch die Art der Zellen lokal verschieden. Ich hebe dies hervor, weil es vielleicht ein Licht wirft auf den Weg, welchen die Exsudation genommen hat. Man ist beim Gefässreichtum der Aderhaut geneigt, diese als Lieferantin des Exsudates, sowohl der flüssigen als der festen Bestandteile anzusehen. Der obige Befund aber weist darauf hin, dass wenigstens in manchen Fällen auch die Gefässe der Sklera an der Lieferung des Exsudates teilnehmen können.

In den bisher betrachteten Fällen, welche das häufigste Vorkommnis darstellen, war der Glaskörper der Ausgangspunkt der Entzündung. Bei der metastatischen Ophthalmie nimmt die Entzündung ihren Ursprung von den Gefässen der Retina, seltener von denen der Uvea. Nehmen wir den einfachsten Fall, dass nur an einer einzigen Stelle der Netzhaut oder Aderhaut eine Embolisierung der Gefässe erfolgt sei. Alsbald entwickelt sich dort eine dichte eitrige Infiltration, welche, wenn der Embolus in der Netzhaut sitzt, sofort auf die Aderhaut übergreift und umgekehrt. Rasch zerfallen hier nun beide Membranen zu einer aus Eiter und Gewebsstücken bestehenden Masse, welche in den Glaskörper vorragt. Von hier geht die Entzündung in der Kontinuität der Aderhaut und Netzhaut nicht weit und spielt daher keine Rolle. Dagegen geht von der in den Glaskörper vorragenden zerfallenden Masse der Entzündungsreiz auf die ganze innere Auskleidung des Glaskörperraumes über und die folgende Entzündung spielt sich daher in derselben Weise ab, wie in den gewöhnlichen Fällen von primärer Infektion des Glaskörpers. Zuerst gerät die Netzhaut in ihrer ganzen Ausdehnung in Entzündung. Wird die Netzhaut dadurch frühzeitig abgehoben, so kann die Aderhaut in den vom Embolus entfernten Teilen in grosser Ausdehnung normal bleiben. Ist die Entzündung in einem solchen Falle abgelaufen, so erkennt man die Stelle des ursprünglichen Herdes leicht daran, dass hier Netzhaut und Aderhaut zusammen in eine derbe Schwiele verwandelt sind, welche die ursprüngliche Struktur dieser Membranen kaum mehr erkennen lässt; im übrigen aber ist die Netzhaut abgehoben und gefaltet, die Aderhaut aber unverändert.

Es kommt sehr selten vor, dass eine eitrige Entziindung des Augeninnern von der hintern Seite ausgeht, da die hintere Ober- 
fläche des Augapfels gewöhnlich weder von Verletzungen noch von spontanen Entzündungen betroffen wird. Überdies bildet die der Eiterung so wenig zugängliche Sklera einen ziemlich sicheren Wall nach aussen. Darum kommt es bei retrobulbärer Phlegmone verhältnismässig selten zum Übergange der Eiterung auf das Augeninnere; ist es doch der Fall, so folgt die Entzündung den die Sklera durchbohrenden Gefässen. Ich habe einen Fall untersucht, in welchem ein Trauma die hintere Oberfläche der Sklera betroffen hatte, und zwar war das Trauma eine Neurotomia optico-ciliaris, bei welcher es zur Infektion der Wunde gekommen war. Das Auge war sechs Jahre vorher infolge von Variola erblindet. Es hatte an Stelle der Hornhaut eine abgeflachte Narbe, der hintere Abschnitt des Auges aber war, wie später die anatomische Untersuchung zeigte, kaum verändert. Die Neurotomie war von rasch zunehmender Vortreibung des Auges mit schweren entzündlichen Erscheinungen gefolgt, so dass fünf Tage nach der Neurotomie das Auge enucleirt wurde. Bei der mikroskopischen Untersuchung erwies sich das episklerale Gewebe im hintern Abschnitte des Auges eitrig infiltriert. Von hier ziehen Züge eitriger Infiltration durch die Sklera bis an die innere Oberfläche derselben. Hie und da bestehen kleine Abscesse in der Dicke der Sklera oder nahe deren innerer Oberfläche (Fig. 10b). Der suprachorioideale Raum $(d)$ ist überall von zellenreichem, an manchen Stellen rein eitrigem Exsudate erfüllt, und auch die Aderhaut $(e)$ ist in ihrer ganzen Ausdehnung dicht infiltriert. Hier aber machen die schwersten entzündlichen Veränderungen Halt. Schon das Pigmentepithel $(f)$ ist grösstenteils intakt. Die seröse Flüssigkeit zwischen Aderhaut und Netzhaut enthält nur vereinzelte Zellen. Mehr Zellen findet man erst wieder in den innern Schichten der Netzhaut $(h)$, vereinzelt auch in den angrenzenden Teilen des Glaskörpers (i). Die Aderhant hat sich also hier als ein ziemlich dichtes Filter bewährt gegenüber den entzündungserregenden Substanzen, welche sie von hinten angreifen, ähnlich wie in den gewöhnlichen Fällen, wo die Entzündungserreger von vorne kommen, die Netzhaut einen Schutz für die Aderhant bildet.

\section{Znsammenfassung.}

Das Ergebnis der obigen Darlegungen lässt sich in folgendem aussprechen: Wenn der Glaskörper infiltriert ist, so verbreitet sich von hier aus der Entzündungsreiz auf die innere Auskleidung des Glaskörperraums, namentlich auf die Pars ciliaris retinae und auf 
die eigentliche Netzhaut. Diese Membranen geraten zuerst in Entziindung: es entsteht eitrige Retinitis in grosser Ausdehung. Eine Wirkung in die Tiefe findet nur dort statt, wo diese innerste Membran mit der nächsten, der Uvea in Zusammenhang ist. Es erkrankt daher regelmässig der Ciliarkörper in seinen oberflächlichen Lagen, während die Aderhaut nur dann in höherem Masse ergriffen wird, wenn die entzündete Netzhaut ihr anliegend bleibt. In den zahlreichen Fällen, wo sich die Netzhaut frühzeitig abhebt, beteiligt sich die Aderhaut nur wenig an der Entzündung. Die Ausbreitung der Entzündung in der Kontinuität der Membran reicht nicht auf grosse Entfernung. Vom Ciliarkörper aus erkrankt der vordere Rand, vom Sehnervenkopfe der hintere Rand der Uvea. Eine Ausnahme macht nur der suprachorioideale Raum, welcher oft in grosser Ausdehnung an der Entzündung teilnimmt, wenn an einer Stelle die Entzündungserreger in ihn eingedrungen sind. Diese Stelle ist der flache Teil des Ciliarkörpers, dessen Stroma hier immer von der damit fest verwachsenen Pars ciliaris retinae her stark entzïndet ist ${ }^{1}$.

1) Die hier beschriebene Ausbreitung der Entzündung über die innern Augenmembranen kommt, obwohl weniger deutlich ausgesprochen, auch vor im Anschlusse an eine primäre nicht eitrige Erkrankung einzelner Teile der Uvea. Von dem primären Herde werden entzündungserregende Substanzen in den Glaskörper ausgeschieden und wirken ron diesem aus auf die innere Oberfläche der Netzhaut. Ich führe als Beispiel zwei von mir untersuchte Fälle syphilitischer Neubildung im vordern Teile der Uvea an. In dem ersten Falle nahm die Neubildung die Iris und den Ciliarkörper in umschriebener Ausdehnung ein. Sie war durch die Sklera nach anssen gewuchert und hatte anderseits stellenweise den retinalen Überzug der Ciliarfortsätze durchbrochen. In diesem Falle besteht im übrigen Umfange des Ciliarkörpers, soweit derselbe in seinem Stroma nicht erkrankt ist, doch eine reichliche zellige Infiltration des retinalen Überzuges, welche Infiltration sich auch auf die Netzhaut ausdehnt. Diese zeigt überall in ihren innern Lagen und wor allem um die Blutgefässe Leukocyten, welche sich auch in den an die Netzhaut angrenzenden äussern Teilen des Glaskörpers finden. Die äussern Netzhautschichten, sowie die darunter liegende Aderhaut sind normal. Diese diffuse Entzündung der Netzhaut ist an der dem syphilitischen Tumor gegenüberliegenden Seite nicht geringer, als an der Seite des Tumors, dagegen nimmt sie von vorn nach hinten allmählich ab. Die Art und Ausbreitung der Entzündung beweist, dass hier die entzündlichen Reize nicht in der Kontinuität der Augenhäute von der syphilitischen Geschwulst aus fortgeschritten waren, sondern vom Glaskörper aus auf die innere Oberfläche der Netzhaut gewirkt hatten. Das dadurch entstandene anatomische Bild gleicht daher demjenigen, welches man nach einer leichten Infektion des Augeninnern durch ein perforierendes Trauma bekommt. - Die gleichen Verhältnisse bestehen im zweiten Falle, wo die syphilitische Neubildung 
Die Darstellung, wie sich die Entzündung im Augeninnern verbreitet, sollte ergänzt werden durch den Nachweis, wie sich dabei die ins Auge gedrungenen Mikroorganismen verhalten. Während die obigen Auseinandersetzungen auf dem Studium einer sehr grossen Zahl von Fällen beruhen, habe ich leider nur eine beschränkte Zahl von Fällen mit brauchbarer Färbung der Bakterien zur Verfügung. Soweit ich aus diesen ersehen kann, hält die Ausbreitung der Bakterien im Auge durchaus nicht gleichen Schritt mit der Ausbreitung der Entzündung. Ich habe bei frischer eitriger Entziundung die Bakterien im Glaskörper, hauptsächlich im vordern Teile desselben gefunden, aber selbst in den Fällen, wo sie geradezu massenhaft im Glaskörper vorhanden waren, lagen sie nicht unmittelbar auf der Netzhaut, und noch weniger waren sie in dieser selbst oder gar in der Aderhaut zu sehen. Die Entzündung der innern Augenhäute beruht also jedenfalls zum Teile auf einer Fernwirkung der Bakterien mittels der von ihnen produzierten Toxine. Manchmal mag dazu auch die schädliche Wirkung kommen, welche die Produkte zerfallenden Gewebes zu entfalten vermögen.

\section{Verdichtung der Suprachorioidea.}

Nach Ablauf schwerer Entzündung der innern Augenhäute bleiben zuweilen, wie auf S. 407 erwähnt, Auflagerungen auf der innern Oberfläche der Aderhaut zurück, noch häufiger aber dauernde Verdichtungen der suprachorioidealen Lamellen. Solche bilden sich ausserdem auch infolge geringer, aber lange einwirkender Reize aus, wie seröser Erguss oder Blutung unter die Aderhaut. Ich werde auch diese Fälle besprechen und beginne damit, die histologischen Vorgänge bei der Verdichtung der Suprachorioidea zu erörtern. In der Literatur findet sich iiber diesen Gegenstand wenig. Schiess ${ }^{1}$ ) hat in einem Falle schwerer Verletzung, welcher sechs Monate später zur Enucleation kam, eine derbe bindegewebige Membran zwischen Aderhaut und Sklera gefunden, welche stellenweise fast $2 \mathrm{~mm}$ Dicke

in den äussern Teilen des Ciliarkörpers sass und aueh durch die Sklera nach aussen gewuchert hatte. Dagegen war sie nach innen noch überall von den unzerstörten Ciliarfortsätzen bedeckt. Dementsprechend war die Entzündung der Netzhaut hier geringer als im ersten Falle, aber doch bestand eine diffuse Infiltration der Pars ciliaris im ganzen Umfange, welche sich allmählich abnehmend in den innern Schichten der Netzhaut weit nach hinten erstreckte.

1) Über fibröse Degeneration und Fibrom der Chorioidea. Virchow s Arch. Bd. XLVI. S. 53. 
erreichte. $\left.\mathrm{Bloom}{ }^{1}\right)$ konstatierte ein ähnliches, wenn auch weniger dickes Häutchen unter der Aderhaut bei blutiger Abhebung derselben, welche zwei Monate vorher stattgefunden hatte. Günsberg ${ }^{2}$ ) erwähnt und zeichnet eine derartige schwielige Verdickung der Suprachorioidea und Greeff ${ }^{3}$ ) gibt ebenfalls eine Abbildung davon und bezeichnet die Veränderung als Obliteration des suprachorioidealen Raumes. Ich selbst ${ }^{4}$ ) habe die Bildung derber Membranen sowohl nach Entzündung als hauptsächlich nach subchorioidealer Blutung unter dem Namen der Suprachorioiditis lkurz beschrieben.

Die histologischen Veränderungen bei der Verdichtung der Suprachorioidea werden verständlich, wenn man sie von ihrem Beginne, dem entzündlichen Ödem der Suprachorioidea, verfolgt. Die zwischen den Lamellen liegenden weissen und roten Blutkörperchen verschwinden allmählich. An Stellen, wo etwas grössere Blutaustritte waren, bleibt häufig hämatogenes Pigment in Form unregelmässiger Schollen und Klumpen zurück. Die zarten verzweigten Pigmentzellen der Suprachorioidea zeigen die gewöhnlich bei Entzündung beobachteten und oft beschriebenen Veränderungen. Sie verlieren ihre Fortsätze, werden plump und das Pigment in ihrem Protoplasma, im normalen $\mathrm{Zu}-$ stande feinkörnig, bäckt zu gröbern Klümpchen zusammen. Man hat dann kuglige Zellen mit grössern Pigmentklumpen neben dem Kern, häufig auch kernlose Protoplasmaklumpen, welche Pigment einschliessen, oder ganz freie Pigmentklumpen.

Die wichtigsten Veränderungen zeigen die Endothelzellen. Von diesen sieht man normalerweise nur die grossen blassen Kerne die sogenannten freien Kerne -, welche von den feinen elastischen Fasern der Suprachorioidea überkreuzt werden. Bei länger bestehender Reizung bemerkt man zuerst ein deutliches Protoplasma mit Ausläufern (Fig. 11b). Diese gehen bald nach verschiedenen Richtungen hin, bald verlaufen sie parallel. Im ersten Falle entsteht durch die Anastomosierung der Ausläufer benachbarter Zellen ein

1) Über retrobulbäre Blutung nach Starextraktion. Dieses Arch. Bd. XLVI. S. 184.

2) Pathologische Histologie des Auges. S. 245.

3) Loc. cit. S. 293.

4) Dieses Arch. Bd. LIII. S. 398. In der Anmerkung auf derselben Seite heisst. es, dass die suprachorioidealen Schwarten viel seltener vorkommen, als diejenigen auf der innern Oberfläche der Aderhaut. Nachdem ich jetzt so viele Fälle der verschiedensten Art durchgesehen habe, stelle ich dies dahin richtig, dass das Verhältnis umgekehrt ist. 
feines Netzwerk (Fig. 11). Im zweiten Falle wird das Gewebe feinfaserig, um so mehr als auch zwischen den Ausläufern der Zellen, in der Intercellularsubstanz, feine Fibrillen auftreten (Fig. 15), welche später zu derben Bindegewebsfasern werden. Diese Entwicklung lässt sich am besten an Präparaten verfolgen, welche nach ran Gieson gefärbt sind, wodurch das Bindegewebe rot wird und sich dadurch von dem ursprünglichen Gewebe der Suprachorioidea unterscheidet. Dieses nimmt keine rote Fürbung an, weil es normalerweise keine leimgebende Substanz enthält (abgesehen von dem Bindegewebe, welches die durch die Suprachorioidea ziehenden Getässe und Nerven begleitet). Man sieht also bei beginnender Verdichtung der Suprachorioidea zwischen den langgestreckten Zellen mit ihren Ausläufern eine rötliche Färbung auftreten, und zwar entweder in gleichmässiger oder in fleckiger Form. Dies ist die leimgebende Substanz, welche hier zuerst in der Intercellularsubstanz in kolloidalem $\mathrm{Zu}$ stande ausgeschieden wird. Bald tritt in derselben eine feine Streifung auf (Fig. 12b), unter deren Zunahme sich allmählich Fibrillen entwickeln. Die Richtung derselben ist wahrscheinlich durch Zugund Druckwirkungen bestimmt, welche im Gewebe herrschen. Da diese auch orientierend auf die suprachorioidealen Lamellen im ganzen und auf deren Zellen und Fasern wirken, ist es begreiflich, dass diese und die neugebildeten Fibrillen im gleichen Sinne orientiert sind, dass also die Fibrillen parallel zur Längsrichtung der Kerne und der von ihnen ausgehenden Protoplasmafortsätze ziehen. Besonders deutlich ist oft die erste Anlage des jungen Bindegewebes in der unmittelbaren Umgebung der zarten neugebildeten Blutgefăsse, deren Wände dadurch verstärkt werden (Fig. $13 b$ u. c).

Das junge Bindegewebe verdichtet sich. später, indem dessen Fasern dicker und straffer werden, die Kerne länger, schmäler und dunkler sich tingierend. Manchmal bilden die Fasern ein dichtes Netzwerk mit wenigen Kernen (Fig. 14), ein andermal liegen die Fasern parallel und dicht aneinander, der Richtung der Chorioidea und der Sklera folgend (Fig. 15). Die suprachorioidealen Lamellen werden allmählich durch solches derbes Gewebe ersetzt, doch bleiben sie noch lange kenntlich an den Zügen von Pigmentzellen, welche manchmal in regelmässigen Lagen mit den neugebildeten Bindegewebsfasern abwechseln. Letztere liegen entweder parallel zu den Zügen von Pigmentzellen, oder sie spannen sich senkrecht zwischen ihnen aus, letzteres, wenn die suprachorioidealen Lamellen gewaltsam auseinandergezogen werden, indem die Aderhaut von der Sklera 
abgezogen ist. (Dies kann auf doppelte Weise geschehen: Es kann die Aderhaut durch den $\mathrm{Zug}$ der Glaskörperschwarten in das Augeninnere gezogen werden, oder die Sklera macht in der Äquatorgegend eine cirkulär herumgehende Falte, wobei die dem Scheitel der Falte entsprechende Stelle der Sklera stark nach aussen ausgebogen und daher von der Aderhaut abgezogen ist.)

Das verdichtete suprachorioideale Gewebe ist von neugebildeten Gefässen durchzogen, deren Zahl ausserordentlich variiert. Sehr schön lässt sich die Entwicklung der Gefässe verfolgen. Zuerst sieht man nur ein Endothelrohr ohne Blut in demselben. Dann werden die Gefässe blutführend, können aber manchmal sehr weit werden, ohne mehr als das Endothelrohr als Wand zu haben. Häufig aber wird die Wand des Gefässes dadurch verstärkt, dass sich Bindegewebsfasern aussen an das Gefässrohr und parallel zu dessen Längsrichtung anlegen und so allmählich eine Adventitia herstellen (Fig. 13). Diese kann ziemlich mächtig werden und in einem Falle habe ich sie sogar hyalin entartet gesehen. Die Gefässe verlaufen bald mehr parallel zur Oberfläche der Sklera und Aderhaut, bald durchsetzen sie quer oder schräg den suprachorioidealen Raum von der Sklera zur Aderhaut oder zum Ciliarkörper. - Die Mehrzahl der neugebildeten Gefässe bezieht ihr Blut aus den vordern und hintern Ciliararterien. In den äquatorialen Teilen des Auges, welche von diesen beiden Gefässbezirken entfernt sind, wachsen auch direkt aus der Sklera kleine Gefässchen in die suprachorioidealen Schwarten hinein, wie ich in mehreren Fällen habe konstatieren können.

In dem verdichteten suprachorioidealen Gewebe treten oft kleinere und grössere Hohlräume auf. Der Anfang wird dadurch gegeben, dass sich aus dem Transsudate, welches den Suprachorioidealraum anfangs in gleichmässiger Weise erfüllt, Tröpfchen anders beschaffener Flüssigkeit ausscheiden. Dieselben erscheinen an den Präparaten, in welchen die gesammte Flüssigkeit im suprachorioidealen Raume geronnen ist, als hellere Vakuolen. Durch Vergrösserung der Tröpfchen werden die Pigment- und Endothelzellen sowie die neugebildeten feinen Fasern der Suprachorioidea auseinandergedrängt und dadurch etwas grössere runde oder elliptische Hohlräume geschaffen (Fig. 16a), wobei auch oft Zerreissung der feinen Fasern und Lamellen der Vergrösserung der Lü̈cken Vorschub leistet. Die angesammelte Flüssigkeit drängt die Zellen und Fasern immer mehr an die Peripherie des Hohlraumes, wodurch sich dessen Wand allmählich verdichtet. Bei grössern Hohlräumen erfährt die Wand 
eine Verstärkung durch neugebildetes Bindegewebe, welches fast niemals fehlt, wenn es sich um grössere, ganz freie Hohlräume handelt. Man bemerkt dieses dichtere Bindegewebe gewöhnlich zuerst am hintern Ende des Hohlraumes, wo es einen auf dem Querschnitte dreieckigen Raum erfüllt (Fig. $\nabla d$ ). Ebenso tritt oft schon frühzeitig auch am vordern Ende des Hoblraumes derartiges Bindegewebe auf (Fig. Vc). Bei grössern länger bestehenden Hohlräumen hat sich endlich eine derbe fibröse Kapsel ringsherum gebildet, welche nach Art einer Cystenwand die angesammelte Flüssigkeit einschliesst (Fig. Vb). Die innere Oberfläche der Kapsel ist glatt und trägt oft eine Art von Endothelbelag (Fig. 17), indem die Zellkerne hier flach nebeneinander auf der Oberfläche der Membran liegen.

Die Verdichtung der suprachorioidealen Lamellen zu derben Membranen findet nicht bloss dort statt, wo grössere Hohlräume sich gebildet haben, sondern manchmal auch inmitten des Netzwerkes, welches den Raum zwischen Sklera einerseits, Ciliarkörper und Aderhaut anderseits erfüllt. Ein anderes Mal wieder verdichtet sich dieses Netzwerk an seiner äussern oder an seiner innern Oberfläche zu einer bindegewebigen Membran, wodurch er sich scharf gegen die Sklera oder gegen die Aderhaut abgrenzt (Fig. 18c). Es kann aber diese Membran auch mit der Sklera oder mit der Aderhaut fest verwachsen sein. Je mehr das anfäng-

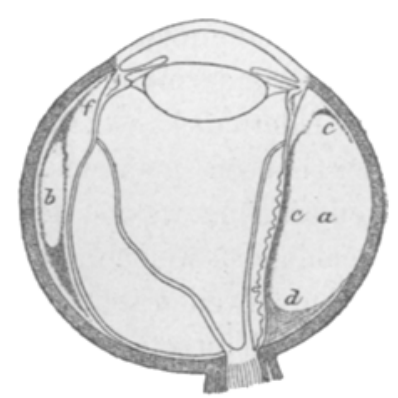

Fig. V. Glaukomiridektomie mit nachfolgender subchorioidealer Blatung vor 1 Monat. Totale Netzhautablosang. Aderhaut anf der nasalen Sotte rollstandig, anf der temporalen grösstenteils durch Blat $a$ a. $b$ abgehoben, $c d^{2} e$ einkapselndes Bindegevebe.

liche Netzwerk zu derben Membranen sich verdichtet, desto mehr verschwinden die suprachorioidealen Pigmentzellen aus demselben, so dass die Membranen mit seltenen Ausnahmen unpigmentiert sind und urur an ihrer Oberfäche von einem Belage von Pigmentzellen bekleidet sind, welche den angrenzenden, noch nicht in Bindegewebe verwandelten suprachorioidealen Lamellen angehören (Fig. 18).

Besonders starke Membranen im suprachorioidealen Raume bilden sich nach subchorioidealer Blutung. Sie beginnen ibre Entwicklung alsbald nach stattgehabtem Blutaustritte, so dass man schon nach 1-2 Wochen junge Membranen antrifft. Dieselben sind succulent, reich an Kernen von elliptischer Form (Endothelkernen) sowie aus diesen hervorgegangenen kurzen spindelförmigen. Zellen; dazwischen liegen Leukocyten und rote Blutkörperchen (Fig. 19c). In den alten 
Membranen sind die Kerne spärlich, schmal, langgestreckt, die Fasern dünn, lang, starr. Je älter die Membran, desto homogener ist ihr Gefüge. Wenn sie auf Grund einer subchorioidealen Blutung entstanden ist, enthält sie hämatogenes Pigment. Spärlicher sind Zellen mit uvealem Pigment zu finden, weil die normalen Pigmentzellen der Suprachorioidea bei der Verdichtung dieser zu Grunde zu gehen pflegen. Wenn sie ausnahmsweise in grösserer Menge erhalten sind, lassen sie durch ihre Anordnung in Schichten erkennen, dass die derbe Bindegewebsmembran aus einer Anzahl übereinanderliegender suprachorioidealer Lamellen entstanden ist. So erklärt sich auch, dass manchmal eine solche Membran aus zwei, nur locker zusammengefügten Lagen besteht.

Die bindegewebigen Membranen im suprachorioidealen Raum können eine Dicke von mehreren Millimetern erreichen, so dass es nicht wundernimmt, dass Schiess einen solchen Fall als Fibrom der Aderhaut beschrieb (loc. cit.). Sie sind gewöhnlich gefässarm oder nahezu gefässlos. Dies ist namentlich die Regel für solche Membranen, welche fest auf der Innenfläche der Sklera aufliegen. Diejenigen, welche die Aderhaut an der hintern Fläche bekleiden, werden zuweilen sehr gefässreich gefunden. Thre Gefässe stammen von den Aderhautgefässen und bilden in der Membran reiche Netze, so dass man zahlreiche Querschnitte von Gefässen in den Präparaten sieht.

Besondere Beachtung verdient das Verhältnis der Bindegewebsmembran zur Aderhaut und Sklera. In der Mehrzahl der Fälle ist sie weder mit der einen noch mit der andern verwachsen, sondern von beiden durch einige lockere suprachorioideale Lamellen getrennt (ich erinnere daran, dass in Fällen frischer Entzündung das Exsudat oft der Hauptsache nach zwischen den mittlern Lamellen der Suprachorioidea angesammelt ist und die innersten und äussersten ziemlich frei lässt. Vergl. S. 411 und Fig. 5 und Fig. 8). Was nun zuerst die Aderhaut anlangt, so liegen wie gesagt zwischen ihr und der Membran gewöhnlich noch die innersten suprachorioidealen Lamellen (Fig. 20b) in ziemlich unverändertèm Zustande, während die Aderhaut (Fig. 20c) darïber gefaltet ist, manchmal in sehr hohem Masse. Die Faltung ist Folge der Zusammenziehung der Membran (doch findet man in atrophischen Augen oft auch Faltung der Aderhaut ohne Gegenwart einer suprachorioidealen Membran). In seltenen Fällen ist die suprachorioideale Membran mit der Aderhaut fest verwachsen und diese ist dann wenig oder nicht gefaltet, ja häufig selbst zu einem fibrösen Gewebe entartet, das sich gegen die suprachorio- 
ideale Membran nicht mehr scharf abgrenzen lässt. Ist die letztere dann auch mit der Sklera verwachsen, so besteht eine wirkliche Obliteration des suprachorioidealen Raumes (Fig. 21), wie sie Greeff beschreibt und zeichnet (vgl. S. 418) ${ }^{1}$ ).

Die Verwachsung der Membran mit der Sklera ist verhältnismässig häufiger als mit der Aderhaut. Manchmal ist die Membran nur an ihrem vordern oder hintern Ende, manchmal in grosser Ausdehnung mit der Sklera verwachsen; immer aber ist die Grenze zwischen beiden gut kenntlich; die aufgelagerte Schwarte ist feinfaseriger und kernreicher als die Sklera. Wenn sich die Schwarte vorn und hinten an die Sklera ansetzt, dazwischen aber frei ist, so kann sie bei späterer Schrumpfung zur Bildung jener Falte der Sklera beitragen, welche man bei atrophischen Augen so häufig in der Äquatorgegend antrifft. - Denselben Bau wie die dicken und ausgedehnten Membranen zeigen kleine Schwielen, welche sowohl nach Entzündung als auch nach Blutung öfter in umschriebener Ausdehnung an der äussern Oberfläche der Aderhaut entstehen. Es ist in diesem Falle die Bindegewebsneubildung eben lokal beschränkt geblieben.

Bezüglich späterer Veränderungen der suprachorioidealen Schwarten fällt auf, dass Verknöcherung derselben nicht vorzukommen scheint. Ich habe sie in keinem meiner zahlreichen Fälle gesehen und sie ist bisher auch nicht beschrieben worden. Dies befremdet um so mehr, als die Verknöcherung so häufig in den Schwarten auf der vordern Fläche der Aderhaut, seltener auch in den Schwarten auf der Oberfläche des Ciliarkörpers und an der hintern Seite der Iris vorkommt. Dagegen fehlt sie - in Analogie mit den suprachorioidealen Schwarten - in den alten Exsudaten auf der andern Fläche der Iris.

Die netzförmige Verdichtung der Suprachorioidea, allenfalls mit einzelnen stärkeren Bindegewebszügen oder stellenweiser Verdichtung zu einer Membran, findet sich häufig in Augen, welche nach schwerer traumatischer Entzündung atrophisch geworden sind. Die Bildung ausgedehnter, scharf abgegrenzter Membranen dagegen trifft man vor allem in Augen mit subchorioidealer Blutung. In solchen Fällen fehlt sie fast nie, vorausgesetzt, dass genügend Zeit nach der Blutung verflossen ist, damit solche Membranen sich bilden konnten. Die ersten

1) $\mathrm{Da}$ die völlige Obliteration des suprachorioidealen Raumes im ganzen selten und dann auch meist auf umschriebene Stellen beschränkt ist, so eignet sich diese Bezeichnung nicht zur Charakterisierung der so hänfigen Membranbildung im suprachorioidealen Raume im allgemeinen. Man könnte dafür besser den Ausdruck Suprachorioiditis oder Chorioiditis externa gebrauchen.

v. Graefe's Archir für Ophthaimologie. LVIrr. 3. 
Anfänge derselben treten schon frühzeitig auf; Fig. 19 zeigt eine derartige junge Membran in einem Auge, in welchem acht Tage vorher die subchorioideale. Blutung aufgetreten war. Solche scharf begrenzte grössere Membranen kommen aber wahrscheinlich auch bei schweren Entzündungen ohne Blutung vor. Ich schliesse dies daraus, dass ich sie einigemale in atrophischen Augen gefunden habe, in welchen ich zwar nicht absolut ausschliessen kann, dass im Anschlusse an die Verletzung eine subchorioideale Blutung bestanden hatte, in welchen aber keine positiven Anhaltspunkte für eine solche Blutung vorlagen: kein Rest von Blut, kein hämatogenes Pigment im suprachorioidealen Raume.

Die subchorioideale Blutung entsteht gewöhnlich nach plötzlicher Herabsetzung des intraokulären Druckes, in der Regel also nach Perforation des Auges. War das Auge früher normal, so tritt eine solche Blutung selten ein. Ich habe nur in wenig derartigen Fällen eine Blutung gesehen, welche zwar ausgebreitet, aber ganz flach war. Dagegen kommt eine solche Blutung sehr leicht zu stande, wenn vor der Perforation Drucksteigerung oder Erkrankung der Gefässwände - oder häufig beides zusammen - bestand. Auf diese Weise entstehen die sogenannten expulsiven Blutungen nach Operationen. Die subchorioideale Blutung muss aber gerade nicht expulsiv sein, d. h. so weit gehen, dass sie die innern Augenhäute herausdrängt. Ich habe Präparate von 16 Fällen, in welchen in glaukomatösen Augen nach Perforation, sei es durch Geschwüre, sei es durch Operation, eine ausgedehnte blutige Aderhautablösung eingetreten war, ohne dass diese bis zum Vorfalle der Augenhäute gediehen wäre. Dazu gehört nicht bloss, dass das Blut unter hohem Drucke austritt, sondern auch, dass die Perforationsöffnung genügend gross sei. Darum kommt die expulsive Blutung vor allem nach Kataraktoperationen vor.

Bei subchorioidealer Blutung ist der Ciliarkörper und die Aderhaut gewöhnlich in weiter Ausdehnung abgehoben und stark in den Glaskörperraum vorgetrieben. Anliegend bleibt die Aderhaut in der Regel nur in der Gegend des hintern Augenpoles, wo sie durch die hintern Ciliararterien an der Sklera festgehalten wird. Das Blut scheidet sich bald in Cruor und Serum. Die Verdichtung der Suprachorioidea beginnt am hintern und vordern Winkel der Abhebung (Fig. $V d u$ u. e). Von den Winkeln aus erstreckt sich eine Membran auf die äussere Oberfläche der Aderhaut $(c)$, sowie auf die innere Oberfläche der Sklera; hier reicht sie indessen gewöhnlich 
nicht so weit wie auf der Aderhaut. Manchmal kommt es zu einer vollkommenen Einkapselung des Blutergusses durch solche Membranen (Fig. Vb). Die Verdichtung der Aderhaut zur bindegewebigen Membran ist wahrscheinlich dadurch zu erklären, dass das ergossene Blut eine reizende Wirkung auf das Gewebe, mit dem es in Berührung tritt, ausübt. Wir sehen ja auch an andern Körperstellen Blut durch Bindegewebe abgekapselt werden.

Es scheint, dass manchmal auch die Ansammlung bloss seröser Flüssigkeit unter der Aderhaut eine ähnliche reizende Wirkung zu entfalten vermag, wodurch die suprachorioidealen Lamellen zu bindegewebigen Membranen verdichtet und dadurch die Flüssigkeit abgekapselt wird. So möchte ich einzelne Fälle deuten, in welchen durch den Zug der schrumpfenden Glaskörperexsudate eine Abhebung der Aderhaut entstanden war und in welchen die subchorioideale seröse Flüssigkeit sich durch derbe Membranen abgekapselt fand. Auch eine Abhebung der Aderhaut nach Operation (Kataraktextraktion oder Iridektomie) kann vielleicht, wenn sie lange besteht, zu den gleichen Veränderungen in der Suprachorioidea tühren.

Erklärung der Abbildungen auf Taf. XI und XII, Fig. 1-21.

Fig. 1. Eitrige Cyclitis. Vergrösserung 150:1. Es besteht nach perforierender Verletzung der Beginn einer Panophthalmitis. Die Zeichnung zeigt den Ciliarkörper etwas hinter seinem Firste. Die eitrige Entzündung ist oberflächlich. Das Exsudat $a$ enthält nebst Eiterzellen zahlreiche Pigmentzellen. und deren Trümmer. An der Spitze des kleinen Fortsatzes sind die beiden Zellenlagen der Pars ciliaris retinae zerstört, bei $b$ die innere Lage abgehoben. Weiter hinten werden beide Lagen $c$ and $d$ allmählich normal. Die Buchten zwischen den kleinen Fortsätzen sind von geronnener Flüssigkeit erfüllt, in welcher vereinzelte Eiterkörperchen schwimmen. Das Stroma des Fortsatzes enthält an dessen Spitze eine grössere Zahl von Exsudatzellen, entsprechend dem Grunde der Bucht nur wenige. e Fasern des Ciliarmuskels.

Fig. 2. Entzündung der Aderhaut neben dem Sehnervenkopfe. Vergrösserung 43:1. Nach Schussverletzung vor 16 Tagen. (Das in Textfigur II dargestellte Ange.) Der Sehnervenkopf ist etwas geschwollen, indem in demselben, namentlich um die Blutgefässe $(a)$, Exsudatzellen angesammelt sind. Die an den Sehnerven angrenzende Netzhaut ist infolge der Schwellung des Sehnervenkopfes in ihren aussern Schichten etwas gefaltet und ist etwas infitriert. Sie ist von der Aderhaut durch Serum getrennt, welches einige der äussern Netzhautläche anliegende Exsudatzellen enthält. Das Pigmentepithel ist nor-mal. Die Aderhaut zeigt eine Infiltration, welche knapp am Sehnervenkopfe am stärksten ist und rasch abnehmend in 1,5 bis $2 \mathrm{~mm}$ Entfernung von der Papille aufhört.

Fig. 3. Entzündung des vordern Randes der Aderhaut. Vergrösserung 50:1. Eitrige Retinitis nach einer vor acht Tagen erfolgten perforierenden Hornhautverletzung (das in Textfigur III dargestellte Auge). Die Ora serrata ist dadurch kenntlich, dass hier die Netzhaut in eine kleine Falte abgehoben ist. Die nach vorn davon liegende Pars ciliaris retinae $a$ ist so dicht von Eiterzellen durchsetzt, dass von den Cylinderzellen dieses Netzhaut- 
teiles nichts mehr zu sehen ist. Diese Infiltration setzt sich, etwas abnehmend, nach hinten in die eigentliche Netzhaut $b$ fort. Die innere Oberflache der Pars ciliaris und der Netzhaut ist von einem weniger zellreichen Exsudate $c c$ bedeckt, worauf weiter nach innen reiner Eiter $d$ folgt. Das Pigmentepithel $e$ ist unter der Pars ciliaris breiter und heller geworden, indem die Pigmentzellen durch Eiterzellen auseinandergedrängt und teilweise in Auflösung begriffen sind. Diese Veränderung hört ziemlich scharf an der Ora serrata auf, hinter welcher das Pigmentepithel $f$ kaum verändert ist. Weniger rasch nehmen die Feränderungen in der Uvea hinter der Ora serrata $a b$. Vor dieser ist die Uvea $g$ (hier flacher Teil des Ciliarkörpers) dicht infiltriert und von Blutextravasaten durchsetzt, hinter dieser ist die Uvea $h$ (hier Chorioidea) weniger entzündet und die Infiltration hört weiter hinten ganz auf. Im subchorioidealen Raume ist nur ganz wenig Exsudat.

Fig. 4. Eitrige Retinitis. Vergrösserung 86:1. Von demselben Falle wie Fig. 3. Eitriges Exsudat $a$ liegt auf der Imnenflache der Netzhaut, sowie innerhalb der hier mächtigen Faserschicht $b$ (es ist eine Netzhautstelle nahe dem Sehnerven gezeichnet). Je weiter man in der Netzhaut nach aussen geht, um so mehr nimmt die Zahl der Exsudatzellen ab. In der Schicht der Stäbchen und Zapfen $c$ sind überhaupt keine vorhanden und nur ganz vereinzelte liegen zwischen dieser Schicht und dem Pigmentepithel $d$. Letzteres ist normal. In der Aderhaut $e$ sind sehr wenig Exsudatzellen (der Kemreichtrum der Aderhaut ist nur scheinbar, weil die Blutgefässe zusammengefallen und daher die Kerne der Gefässwände einander angenähert sind).

Fig. 5. Eitriges Exsudat im Suprachorioidealraum. Vergrösserung 165:1. Eitrige Entzündung nach perforierender Verletzung durch einen Zündhütchensplitter vor 15 Tagen. Die in Eiterung begriffene Netzhaut ist weit abgehoben, die subretinale Flussigkeit fast zellenfrei beide in der Figur nicht dargestellt). Die Choriocapillaris a zeigt keine, die folgenden Schichten der Aderhaut wenig Infiltration. Diese wird erst reichlicher in den der Aderhaut noch anliegenden suprachorioidealen Lamellen $b$. Darauf folgen, getrennt durch eine schmale Schicht serösen Ergusses $c$, die Lamellen $d$, welche durch zahlreiche, schon grösstenteils in Zerfall begriffene Eiterzellen mit einzelnen roten Blutkörperchen auseinandergedrängt sind. Die äussersten Lamellen der Suprachorioidea e enthalten wieder mehr zellarmes Exsudat, die Sklera $f$ ist normal.

Fig. 6. Eitrige Chorioiditis. Vergrösserung 135:1. Verletzung durch einen Eisensplitter vor vier Tagen. Es bestand Ringabscess und ausgedehnte eitrige Retinitis. An der gezeichneten Stelle ist nach Zerstörung der Netzhaut die Aderhaut in Fiterung begriffen. Das Pigmentepithel ist zu Grunde gegangen, die Struktur der Aderhant $a$ ist durch Eiterzellen ganz verdeckt und bei $b$ ist die Aderhaut geradezu in einer Abscess verwandelt. Auch zwischen den innersten Lamellen der Suprachorioidea $c$ liegt noch Eiter und diese sind daher nur als Züge von Pigmentzellen in dem eitrigen Exsudat zu erkennen. Die mittlern Lamellen $d$ und die äussern $e$ enthalten Exsudat, das immer weniger zellenreich wird. Die innersten Lagen der Sklera $f$ sind nahezu normal, während die mittlern Lagen $g$ sowie die in der Zeichnung nicht mehr dargestellten äussern Lagen eine ziemlich starke Infiltration, teilweise mit Eiterzellen, aufweisen.

Fig. 7. Tmsehriebener Entzündungsherd in der Aderhaut. Vergrösserung 78:1. Verletzung vor neun Tagen durch einen Kapselsplitter, welcher an der gezeichneten. Stelle nahe dem Sehnerven an die Netzhaut anflog, dieselbe durchbohrte und die Innenfläche der Aderhaut verletzte, und dann in den untern Teil des Glaskörpers fiel. Das Pigmentepithel und die Glasmembran haben eine Lücke, durch welche das Exsudat a aus der Aderhaut über deren Oberfläche empordringt und sich hier pilzförmig ausbreitet. Das Exsudat besteht aus einkernigen Zellen und enthält ausserdem Pigmentzellen und Pigmentschollen, welche vom Pigmentepithel herstammen. Dieses ist in der Nachbarschaft des Loches von dem darüber liegenden Exsudate in Unordnung gebracht und teilweise zerstört. Die Aderhaut ist unter dem Loche so dicht infiltriert, dass man von ihren normalen Gewebselementen nichts mehr 
sieht, ausser einer kleinen Arterie in den äussern Schichten. Die Infiltration der Aderhaut geht in der Dicke der Membran noch eine Strecke weit in die Umgebung hinaus, dagegen setzt sich die Infiltration kaum auf die Suprachorioidea fort und ebenso ist auch kein freies Exsudat in dem Suprachorioidealraume vorhanden.

Fig. 8. Fibrinöses Exsudat im Suprachorioidealraume. Vergrösserung 150:1. Eitrige Entzündung nach einer vor 15 Tagen vollzogenen Staroperation. Unter der eitrig entzündeten, in der Figur nicht mehr abgebildeten Netzhaut sind die Zellen des Pigmentepithels $a$ von der Glasmembran durch Exsudat abgehoben, auseinander geworfen und teilweise zerstört. Die Glasmembran $b$ hat eine Lücke. Die Choriocapillaris $e$ ist am meisten infiltriert, die tiefern Lagen der Aderhaut $d$ und die ihr anliegenden vordersten Lamellen der Suprachorioidea $e$ viel weniger. Dagegen liegt zwischen den folgenden Lamellen $f$ ein reichliches Exsudat, das ans netzförmig geronnenem Fibrin und aus Zellen besteht. Zwischen diesem und der Sklera $h$ liegen wieder einige kaum veränderte Lamellen $g$.

Fig. 9. Exsudat im Suprachorioidealraume. Vergrösserung 86:1. Eitrige Entzündung nach perforierender Verletzung. Die Netzhaut, in der Figur nicht dargestellt, ist in eitriger Entzündung begriffen und durch ein fast zellfreies Exsudat von der Aderhaut abgehoben. Das Pigmentepithel $a$ ist ziemlich normal. In der Aderhaut $b$ liegen einzelne Exsndatzellen. Der suprachorioideale Raum ist durch ein in'der Härtungsflüssigkeit geronnenes Exsudat erfüllt. Dasselbe enthält zahlreiche rote und etwas weniger weisse Blutkörperchen (zumeist einkernige) sowie die suprachorioidealen Lamellen $c c$. Letztere sind durcheinander geworfen und zerrissen. $d$ Sklera.

Fig. 10. Entzündung, von der Sklera ausgehend. Vergrösserung 39:1. Fünf Tage nach einer von Wundinfektion gefolgten Neurotomia optico-ciliaris. Die gezeichnete Stelle liegt nahe dem Sehnerven. Die hintern Sklerallamellen $a$, etwa einem Drittel der Dicke der ganzen Sklera entsprechend, sehen bei oberflächlicher Betrachtung normal aus; da sie aber keine tingierten Kerne aufweisen, sind sie als nekrotisch anzusehen. Die innern Lamellen der Sklera $b$ sind so dicht von Eiterzellen durchsetzt, dass sie gleichsam in eine Konfluierende Eitermasse verwandelt sind, in welcher man noch einzelne Fasern der Sklera $c$ erkennt, sowie nach innen das Pigment der hintersten suprachorioidealen Lamellen, welche in diesen Abscess einbezogen sind. Die mittlern und vordern suprachorioidealen Lamellen $d$ sowie die Aderhaut $e$ sind etwas weniger stark von Exsudatzellen, hier zumeist einkernigen, eingenommen. Das Pigmentepithel $f$ ist normal; zwischen $i h m$ und der Netzhaut liegt eine Spur geronnener Flüssigkeit. Die hintern Netzhautschichten $g$ sind nahezu normal, die vordern Schichten $h$ (Ganglienzellen- und Faserschicht) schliessen wieder Exsudatzellen in mässiger Menge ein, welche von hier aus in die äussern Schichten des Glaskörpers $i$ eindringen.

Fig. 11. Verdichtang der Suprachorioidea zu netzförmigem Gewebe. Vergrösserung 500:1. Atrophischer Bulbus, a Endothelkerne, einige mit deutlichem Protoplasmaleibe $b$, von welchem Ausläufer ausgehen, die mit den Ausläufern benachbarter Zellen ein feines Netzwerk bilden.

Fig. 12. Fntwicklung des Bindegewebes in der Suprachorioidea. Vergrösserung 525:1. Verletzung durch ein Eisenstück vor zwei Monaten. $a$ Kerne der Endothelzellen. Die Intercellularsubstanz $b$ ist teils noch homogen, teils zeigt sie eine Andeutung von Streifung und erweist sich durch ihre Rotfärbung nach van Gieson als junges Bindegewebe.

Fig. 13. Entwicklung des Bindegewebes in der Nachbarschaft eines Blutgefässes. Vergrösserung 525:1. Von demselben Auge wie Fig. 12. In der verdichteten Suprachorioidea verläuft das nengebildete Blutgefäss $a \alpha$, dessen Endothelkerne in das Lumen vorspringen. Zu beiden Seiten des Gefässes hat die Grundsubstanz sich verdichtet $b b$, eine feine Faserung angenommen und tingiert sich nach van Gies on rot. Feine Züge jungen Bindegewebes $c c$ gehen davon in die Ungebung aus. $d$ einkerniger Leukocyt, $e$ hämatogenes Pigment. 
Fig. 14. Älteres netzförmiges Bindegewebe aus dem suprachorioi dealen Raume. Vergrösserung 270:1. Atrophia bulbi nach perforierender Verletzung.

Fig. 15. Älteres längsfaseriges Bindegewebe aus dem suprachorioidealen Raume. Vergrösserung 340:1. Atrophia bulbi nach einer vor einem Jahre vollzogenen Staroperation. a Endothelkerne, lang und schmal, mit deutlichem Protoplasmaleib, der in feine Auslänfer übergeht. $b$ hämatogenes Pigment, $c$ Leukocyten.

Fig. 16. Hohlräume in der netzförmig verdichteten Suprachorioidea. Vergrösserung 140:1. Von demselben Auge wie Fig. 11. Die in den Hohlräumen $a a$ angesammelte Flüssigkeit drängt die Zellen und Fasern des Netzwerkes in konzentrische Lagen zusammen. In der Grundsubstanz feine netzförmige Faserung und einzelne Leukocytenkerne.

Fig. 17. Wand einer Hohle in der verdichteten Suprachorioidea. Vergrösserung 310:1. Atrophia bulbi nach Verletzung. An der innern Oberflache der Höle liegen Endothelzellen, deren Kerne a im optischen Querschnitte längsoval sind und eine äquatoriale Granulierung zeigen. Unter dem Endothelbelag streifiges Bindegewebe.

Fig. 18. Verdichtung der Suprachorioidea. Vergrösserung 60:1. Atrophia bulbi. Nach vorn von der Sklera $a$ folgt mehr lockeres Bindegewebe $b$, welches sich nach vorn allmählich $\mathrm{zu}$ einer festen Schwarte $e$ verdichtet, an deren Oberfläche Pigmentzellen liegen. Darauf folgen die vordersten, nahezu normalen suprachorioidealen Lamellen $d$ und dann die Chorioidea $e$, welche durch Atrophie zu einem dünnen, fast gefäss- und kernlosen Häutchen geworden ist.

Fig. 19. Junge bindegewebige Membran im suprachorioidealen Raume. Vergrösserung 180:1. Subchorioideale Blutung vor sieben Tagen im Anschlusse an eine Iridektomie. $a$ Sklera, $b$ geronnenes Blutserum, $c$ Membran aus suprachorioidealen Lamellen hervorgegangen mit noch wenig ausgeprägter Streifung und mit Zellkernen, welche den Endothelkernen noch ähnlich sind.

Fig. 20. Faltung der Aderhant durch eine suprachorioideale Schwarte. Vergrösserung 50:1. Iridektomie vor einem Monat wegen Glankom, darauf subchorioideale Blutung. Die Schwarte $a$ besteht aus derbem Bindegewebe, darauf folgen die vordern stark pigmentierten Lagen der Suprachorioidea $b$, endlich die Aderhaut selbst $c$.

Fig. 21. Obliteration des suprachorioidealen Raumes. Vergrösserung 180:1. Atrophisches Auge. Die Sklera $a$ steht in fester Verbindung mit der Schwarte, deren hintere Lagen $b$ etwas lockerer und kernreicher, deren vordere Lagen $d$ dichter sind. $c$ Blutgefüss. Die Verdichtung des Gewebes geht ohne Grenze über auf die äussern Schichten der Aderhaut, von welcher nù mehr die Choriocapillaris $e$, auch stark verändert, deutlich zu erkennen ist. 

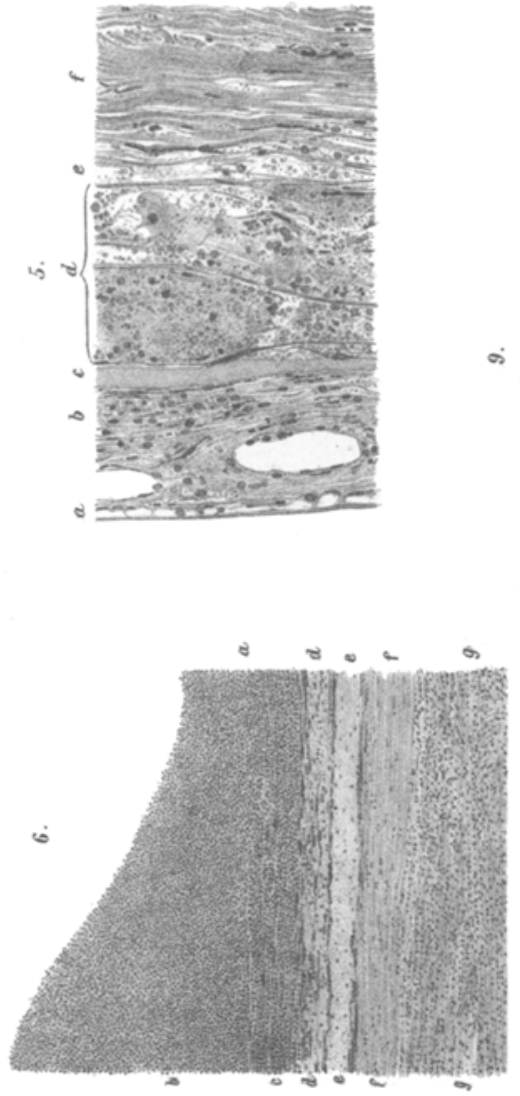
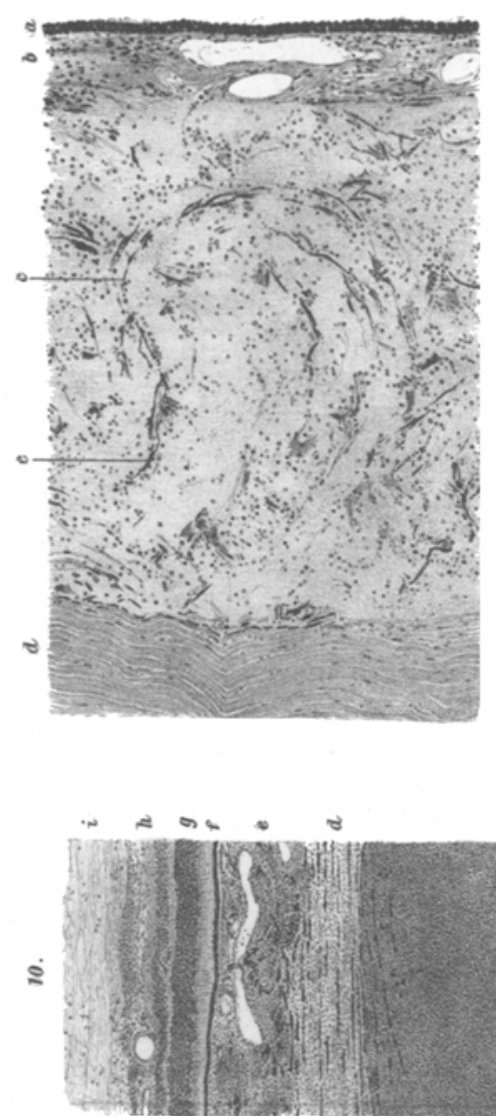

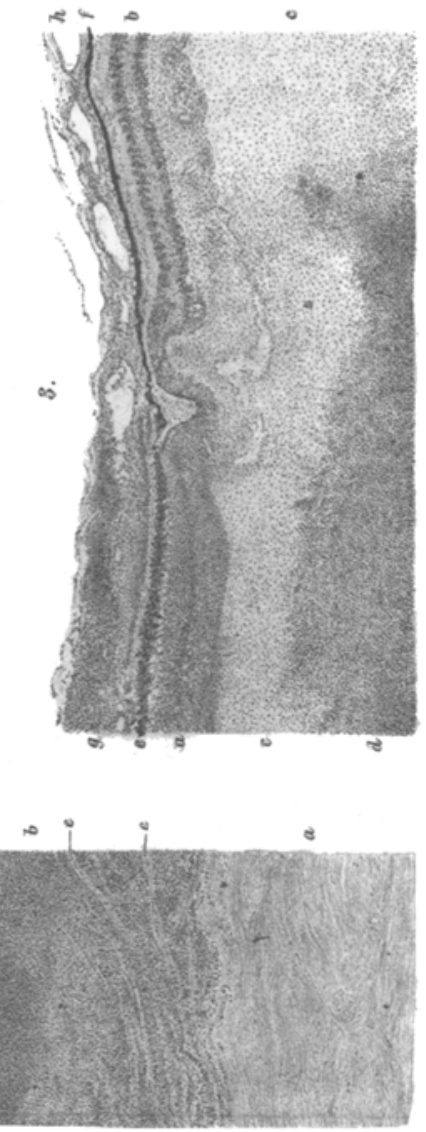

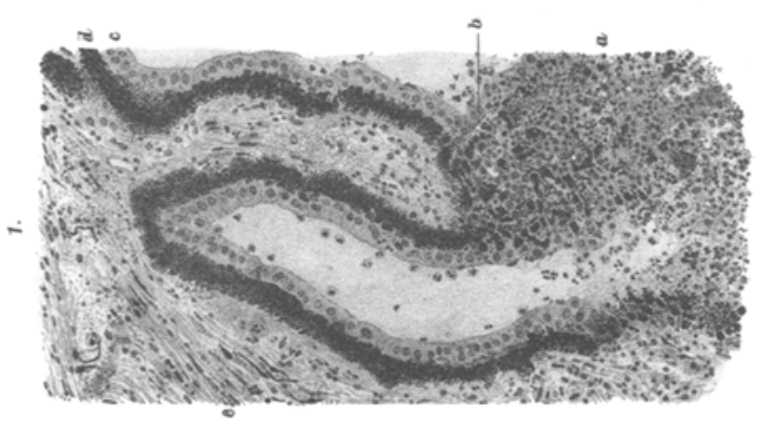

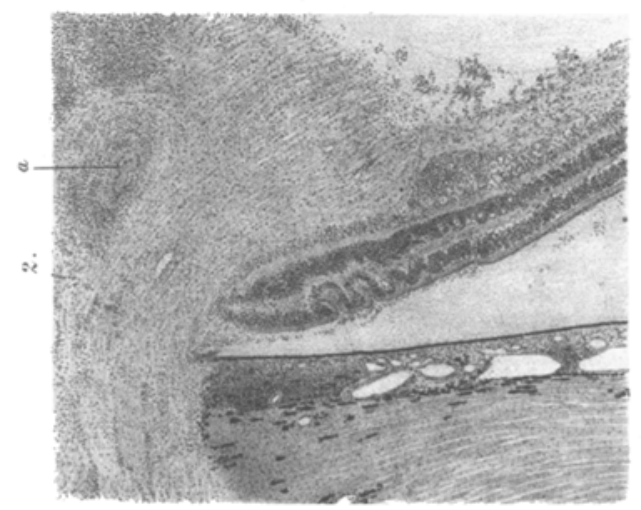

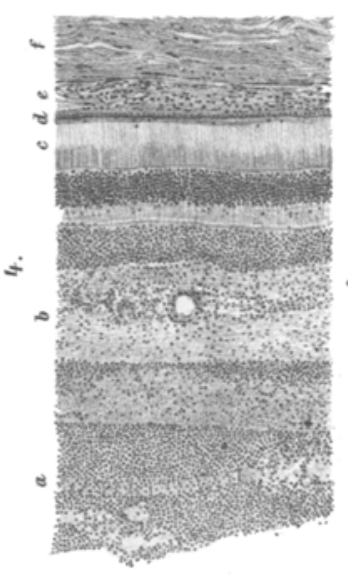

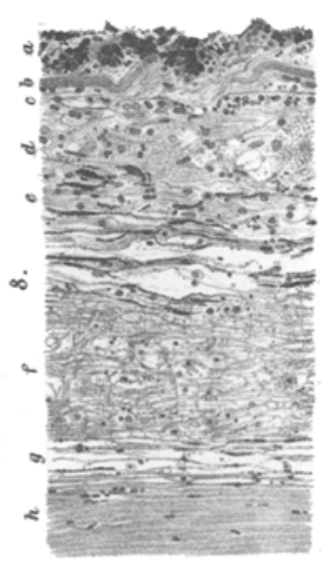

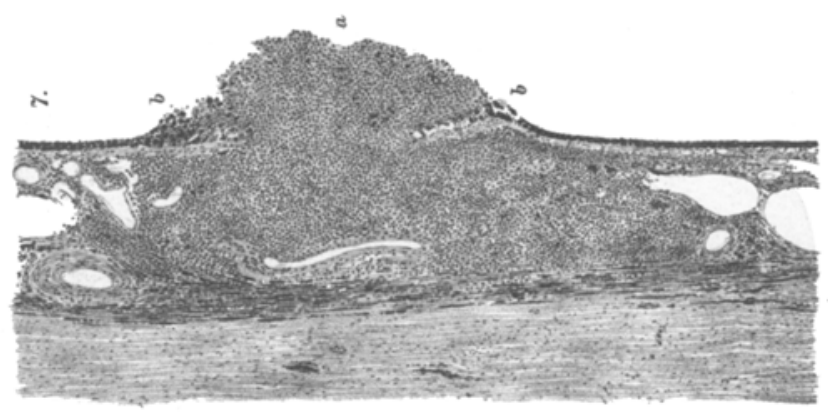


s
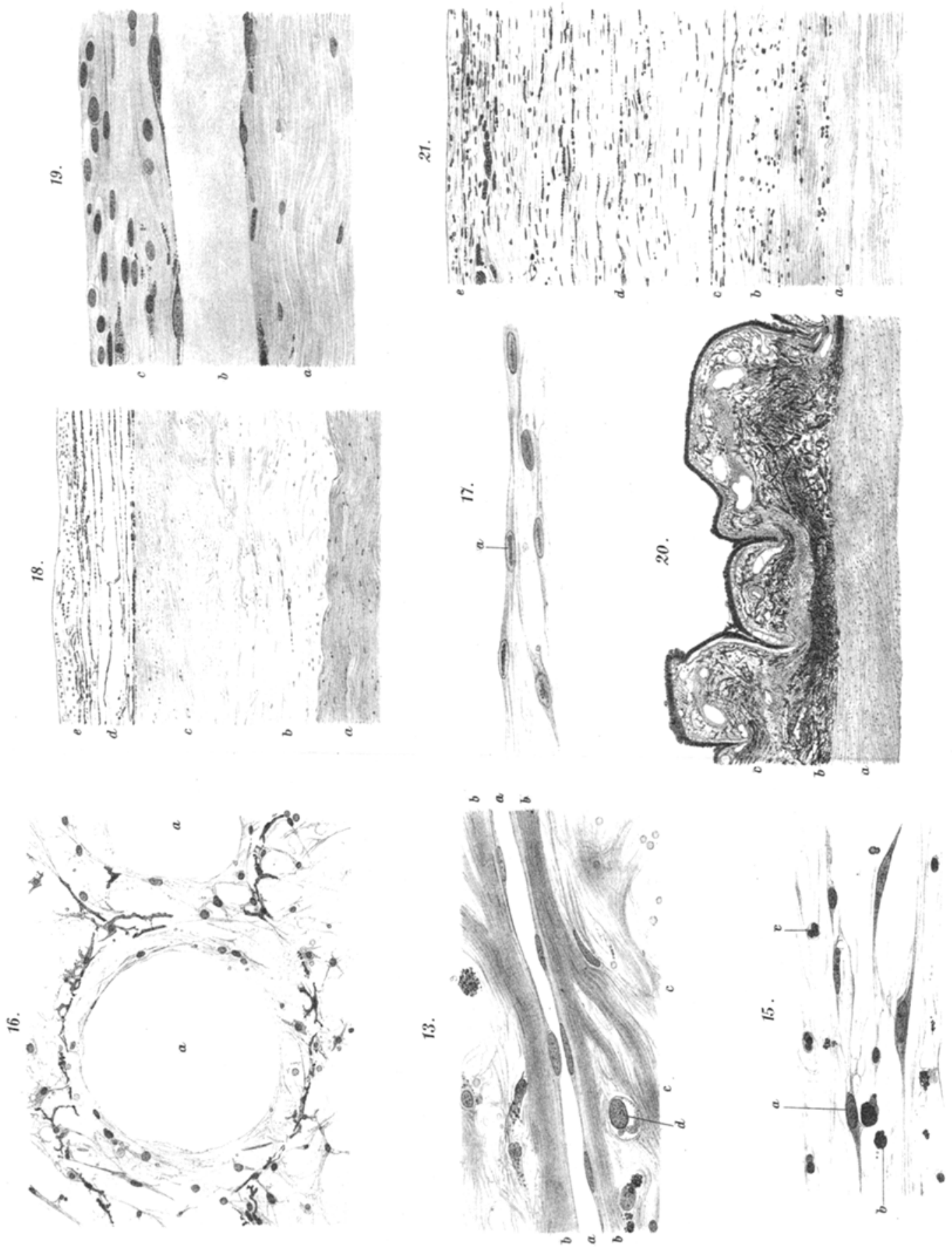

है

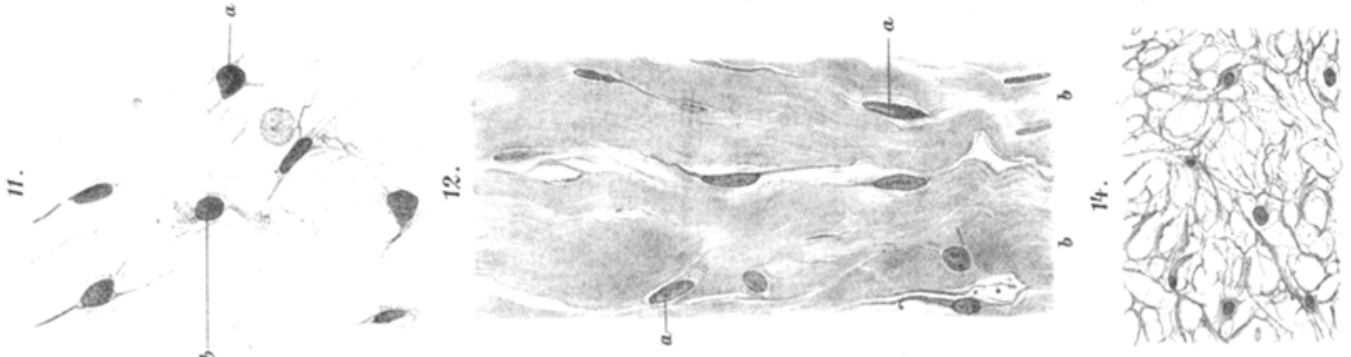

